\title{
A Detailed Presentation of the Theory, Methods and Empirical Findings in the e-book An Introduction to Macroeconomic Models in Excel: A Data-Driven, Arithmetic Approach for Principles of Economics Students
}

\author{
Marc Rubin \\ Towson University
}

The focus of this article is on highlighting the principal results contained in the recently published ebook: An Introduction to Macroeconomic Models in Excel: A Data-Driven, Arithmetic Approach for Principles of Economics Students. The discussion below will present the key empirical findings and the most important steps in the methodological approach. A secondary title for the book could be: Examining the Operating Principles, Calculation Routines, and Data Requirements that Together Constitute a Functioning, Entry-level, Macro Model Tool Kit (set of templates). Students who study these templates will acquire the practical ability to do qualitative analysis of current macroeconomic trends.

Keywords: Entry-Level Macroeconomic Model Tool Kit

\section{INTRODUCTION}

Because the materials in this book are copyrighted and hence proprietary, some of the comments made in this article will necessarily be of a general or "illustrative" nature. Nevertheless, there would be no rationale for subjecting the reader to any of the time consuming hypothetical exercises used here to bypass the copyright issue, unless the actual data and models produced realistic, analytically interesting results. Throughout the text, the reader will encounter references to "tabs" found in the master Excel file. Please see the first endnote for the procedures that allow one to obtain all of these basic source materials from the publisher Kendall Hunt. ${ }^{1}$

\section{SUMMARY: EMPIRICAL EVALUATION OF MODEL FEATURES, PREDICTIONS AND EXPLANATIONS}

Justification for the book is derived from its "bottom line" empirical findings; its contextual basis; and its theoretical significance. This approach leads to the conclusion that the templates are a generally reliable guide for what is likely to happen in the macro economy one quarter ahead (Aggregate Expenditure models, AE) or explanations for what has already occurred (Aggregate Demand-Aggregate Supply models, ADAS). The evaluation of the actual record is structured around both internal and external criteria described next. 


\title{
INTERNAL CONSIDERATIONS: SIGN CONSISTENCY TESTS
}

\author{
AE Models \\ - Nominal Dollar Output (Tab 2): Sign consistency between the "Balance" and $\Delta$ GDP: 100\% \\ - Constant Dollar Output (Tab 102): Sign consistency between the "Balance" and $\Delta$ GDP: 85\% \\ - Constant Dollar CA Output (Tab 117): Sign consistency between the "Balance" and $\Delta$ GNP: \\ $\mathbf{9 2 \%}$
}

\begin{abstract}
ADAS Models
- Price (GDP Deflator): Ceteris paribus multiplier: Sign consistency between "excess demand" and $\triangle$ GDP Deflator: $\mathbf{7 7 \%}$

- Price (GDP Deflator): MACE multiplier: Sign consistency between "excess demand" and $\Delta$ GDP Deflator: $92 \%$

- Inflation rate (Tab 24): Sign consistency between $\% \Delta$ "excess demand" and $\% \Delta$ "GDP Deflator": $54 \%$

- Inflation rate (Tab 24b): Sign consistency between $\% \Delta$ "excess demand" and \% $\%$ "GDP Deflator": $\mathbf{5 8 \%}$ with data smoothing.
\end{abstract}

\section{INTERNAL CONSIDERATIONS: PROVISIONAL ADAS ASSESSMENT OF THE DIRECTION OF THE INFLATION RATE VERSUS THE ANALYSIS OF ITS LEVEL}

Being only somewhat better than chance, the explanatory power of the inflation rate models is ultimately disappointing ${ }^{2}$. But on closer inspection, it may be possible to use the existing framework to cope with this issue. We note that sign consistency is $75 \%$ through the fourth quarter of 2017 . However, in 2018 Q1, the "Trump" tax cuts begin and the model explanations deteriorate dramatically. While there may be some temptation to invoke dummy variables or some other "Deus ex Machina" type explanation at this point, there is no need to wander outside the tool kit. Instead one can explore how the normal rhythms of the macro economy might have been disrupted by the presence of two significant and largely coincident events: the Trump tax cut expenditure stimulus and the arrival of an apparent inflection point in the slope of the AS curve.

Figure 17 below and its counterpart in the master Excel file (Template IV (Tab 67), both portray the economy pressing up against capacity constraints. When this empirical fact about the implied slope of the AS curve is considered in conjunction with the price formation mechanism depicted in Figure 12 and Tab 24 , an interesting possibility arises ${ }^{3}$

Perhaps, the determination of the level of prices, where AD intersects AS in the latter's vertical region also determines the rate of inflation. When graphed, a $4.8 \%$ increase in the AD curve should push the GDP price deflator up from an initial value, of say100, to a new equilibrium level of 104.8, provided the intersection is in the vertical portion of the AS curve, which also happens to be stationary. Conversely, if the AD curve is held constant while the vertical AS curve shifts right, by say $1.1 \%$, the level of the price deflator, beginning at 100, might drop to 98.9 because the intersection of the static AD and mobile AS curves now takes place in a lower segment of the latter, shifting curve. Finally, consider what happens when both the AD and AS curves shift simultaneously: then the forces for a price increases are offset to some extent by those causing price levels to drop. The combined effect on prices in the above example becomes the net of the two shifts (104.8-101.1) (or \% $\% \mathrm{AD}-\% \Delta \mathrm{AS}$ ). In this example, the GDP deflator should settle at a level of 103.7. This leads to the conclusion that AS verticality, and a harmless assumption that the initial price level can be set at 100, necessarily produces an inflation rate of $3.7 \%$.

To illustrate this conjecture over time, return to the hypothetical example and consider all of the data contained in Figure 1 (common ADAS calculation table) in conjunction with all of the data from Figure 2 (slope of the AS curve). The former has the following estimates for the $\%$ shifts in AS and AD. 
FIGURE 1

HYPOTHETICAL AGGREGATE SUPPLY AND AGGREGATE DEMAND SHIFTS

\begin{tabular}{|l|c|c|c|c|}
\hline & & 2015 IV & 2016 I & 2016 II \\
\hline $\begin{array}{l}\text { Hypothetical \% AS } \\
\text { Shift }\end{array}$ & & 0.005 & 0.0046 & 0.011 \\
\hline $\begin{array}{l}\text { Hypothetical \% AD } \\
\text { Shift }\end{array}$ & & 0.01916 & 0.01916 & 0.048172 \\
\hline
\end{tabular}

The "hypotheticals" below detect the presence of capacity constraints with the following data series:

FIGURE 2

TAYLOR RULE AND DETECTION OF CAPACITY CONSTRAINTS

\begin{tabular}{|l|c|c|c|}
\hline Implied Taylor Rule Approach & $\mathbf{2 0 1 5}$ IV & $\mathbf{2 0 1 6}$ I & 2016 II \\
\hline Potential Real GDP & 1770000 & 1775000 & 1780000 \\
\hline Actual Real GDP & 1775000 & 1785000 & 1795000 \\
\hline Potential GDP \% gap & 0.002825 & 0.005634 & 0.008427 \\
\hline \% Change in Implicit Price Deflator & 0.1000 & 0.2000 & 0.3000 \\
\hline Inflation and Unemployment Rule of Thumb & & & \\
\hline $\begin{array}{l}\text { If NRU/ARU >1, AS curve is at an inflationary inflection } \\
\text { point }\end{array}$ & 1 & 1.111111 & 1.225 \\
\hline
\end{tabular}

Paralleling these examples, the real data from the actual Template IV (Tab 67), beginning in 2018 Q2, indicate that both the Natural Rate of Unemployment and the Potential Output variables are signaling that the macro economy is producing at non-sustainable levels, i.e. the AS curve is approaching verticality. Intuitively, one would expect higher and higher rates of inflation to emerge as long as the AS curve is also stationary.

But factually speaking, neither AS stationarity nor high rates of price growth is observed. Tabs 67 a and $67 \mathrm{~b}$ explore this issue in more depth. Tab 67a posits that the AS curve is both vertical and simultaneously shifting to the right. Under these circumstances, the graphical analysis discussed above is relevant, and the resulting rate of inflation can again be calculated as the difference between the rate at which AD shifts right minus the rate at which AS shifts right. The empirical basis for the assumption of a rightward shift in AS is borne out in Tab $67 \mathrm{~b}$. There one can confidently rule out the possibility that observed changes in AS are merely movements along a given AS curve. This conclusion is demonstrated by decomposing the growth rate of AS into the growth of the average productivity of labor and the growth of the labor input, measured either as total labor hours or the number of people employed. Since all three variables exhibit positive growth, the AS curve, must necessarily be shifting to the right.

Actual inflation rate calculations are provided in the following graphic: 
FIGURE 3

PREDICTED VERSUS ACTUAL LEVEL OF INFLATION

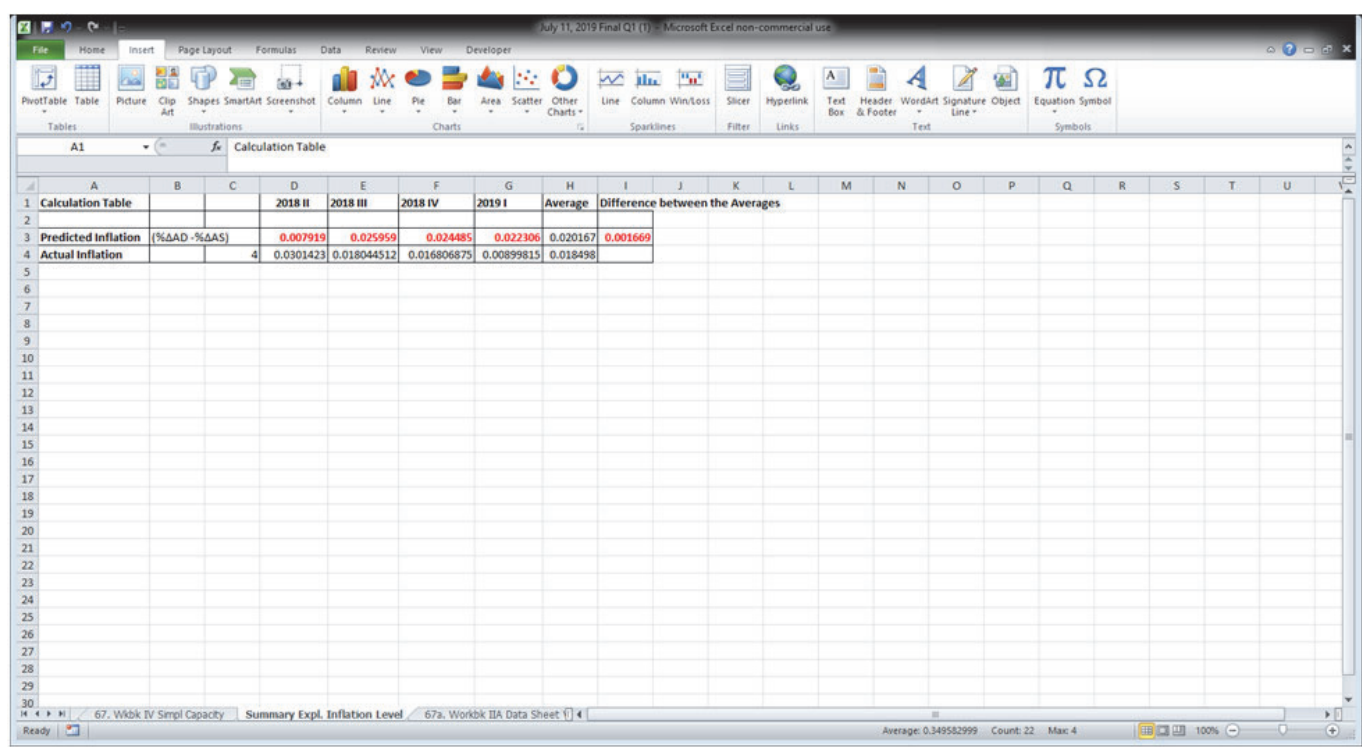

Observe that for the four quarters under investigation, the predicted rate of inflation is quite low and nearly matches the actual rate. In fact, the average difference between the two rates is under 0.2 percent. Simply put, explaining the direction of the inflation rate may be daunting at present, but explaining its low levels seems to be amenable to analysis using the tools currently at our disposal.

\section{EXTERNAL CONSIDERATIONS: MAGNITUDE OF THE ESTIMATED MULTIPLIERS}

Many of the above cited ADAS calculations depend on the use of the multiplier. Because of this fact, it follows that if the magnitudes of the estimated multipliers from the AE templates are unrealistic, the linked ADAS model predictions and explanations may not be fully reliable.

There are four templates where these initial multiplier calculations are performed: a) Nominal dollar AE Model: Template I (Tab 2), b) Constant dollar AE Model: Template VI.1 (Tab 102), c) Nominal dollar AE Model on CA: Template VI.3 (Tab 114), and d) Constant dollar AE Model on CA: Template VI.4 (Tab 117).

To establish the credibility of the template multiplier estimates, comparisons are made with the following numbers reported in a sample of a few of the most popular introductory macroeconomics textbooks.

Baumol and Blinder: multiplier for $\mathbf{G}$ ranges from $\mathbf{0 . 8}$ to 1.5. Page 184. Best guess for multiplier is 1.5 see page 222 .

McConnell, Brue and Flynn: all versions of the multiplier fall into a range between "0" and "2.5". Page 216 ,

Krugman and Wells: page 319 approx. 3, but does not account for leakages from the foreign trade sector, interest rate effects, induced tax revenue changes or overall increases in the GDP deflator.

Krugman and Wells: page 393.... the fiscal multiplier is approx. 1.8.

Case, Fair, Oster: page $297 \ldots$...probably around "2" for government expenditures once the stimulus effects have been fully phased in. 
The next figure contains a summary of the actual template findings.

FIGURE 4

EMPIRICAL MULTIPLIER ESTIMATES

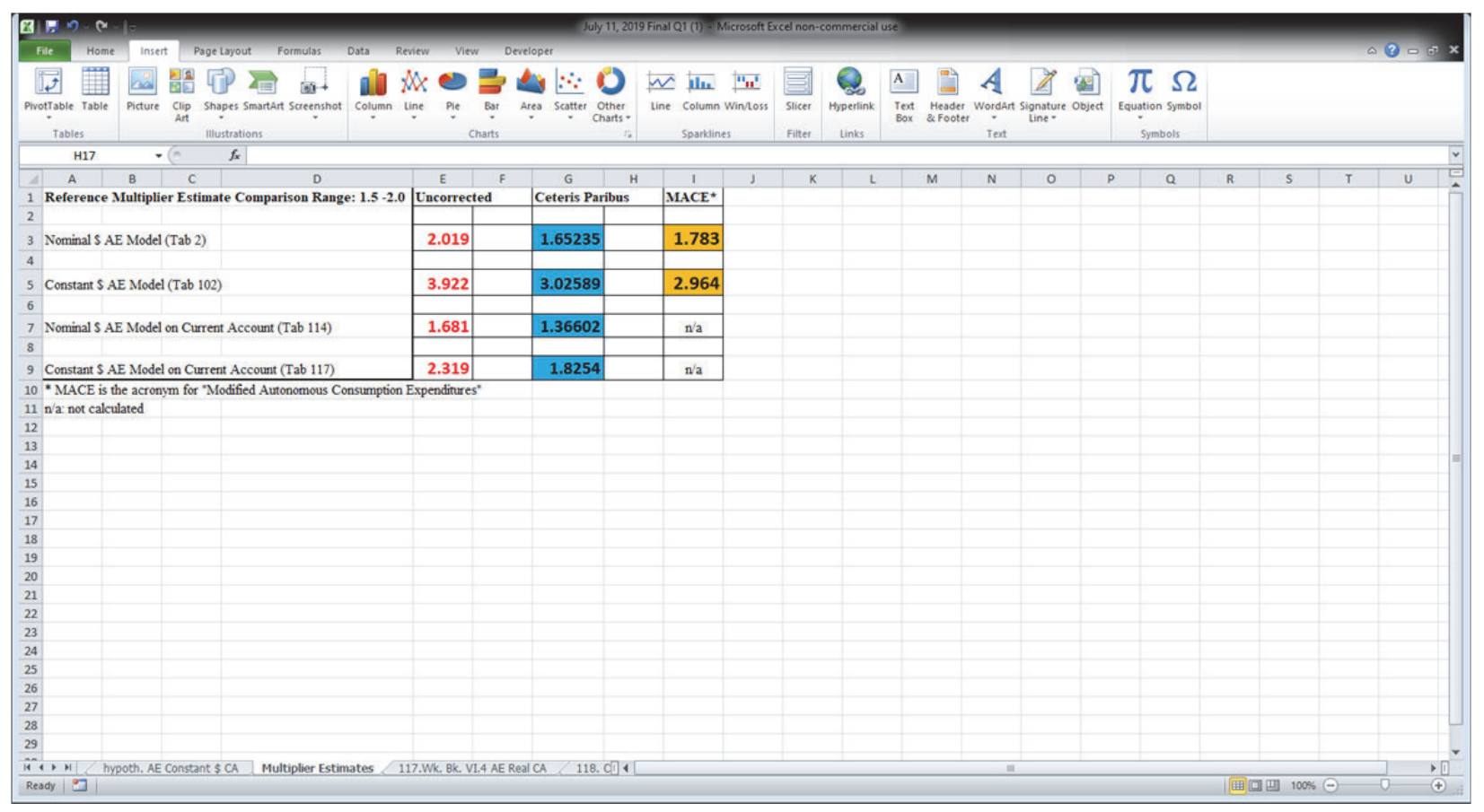

In our opinion the template estimates for the fiscal multiplier ${ }^{4}$ are generally reliable. Three of the four templates in the above table have corrected estimates (Ceteris Paribus and MACE) that fall comfortably within the guide post range (1.5 - 2.0) for the fiscal multiplier. The sole exception is the Constant Dollar AE (Template VI.1 Tab 102) where the magnitudes are too high, hovering around "3". But perhaps the conversion to constant dollars is not really an issue after all. The more general model, constant dollar AE, calculated on current account (Template VI.4, Tab 117), produces a corrected estimate of $\mathbf{1 . 8 5}$.

\section{EXTERNAL CONSIDERATIONS: EXPLAINING THE LONG RUN POSITIVE TREND IN AGGREGATE PRICE LEVELS}

Over the past $4+$ decades, the annual level of the GDP Price Deflator has, with rare exception, increased monotonically. Commentary in the student textbooks has been fairly limited and not entirely illuminating. But this phenomenon can be explained numerically by the "templates". Begin with the graph in Figure 5 below and calculate the "excess demand" at any given price level, then determine whether the implied equilibrium price level is apt to be higher. For instance, at price level $\mathrm{p}=80$, AS might be 500 and $\mathrm{AD}, 1250$. Resulting excess demand of 750 could cause the price level to rise to $p=100$. Immediately below Figure 5 is a table (Figure 6) using actual data from the master Excel file. Because it contains the dates, price levels, and magnitudes for $\mathrm{AD}$ and $\mathrm{AS}$, it can also be plotted in a manner equivalent to the hypothetical graph just discussed ${ }^{5}$.Thus, the tabular exercise visually corroborates our excess demand interpretation of long run monotonic increases in the price level. 


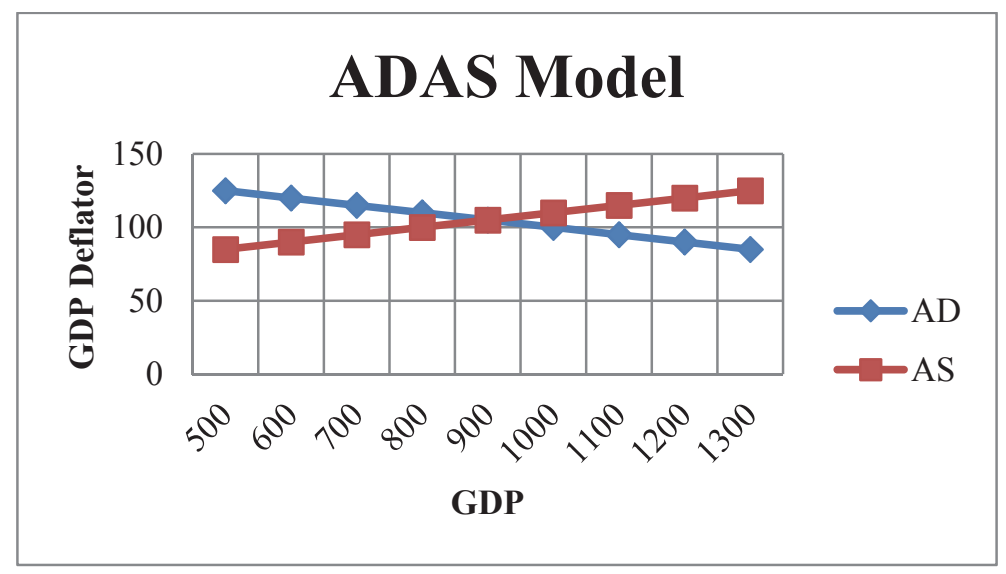

FIGURE 6

ACTUAL CUMULATIVE AD AND AS DATA TABLE

\begin{tabular}{|l|c|c|}
\hline Data Table for Figure 8 in Text & $\mathbf{2 0 1 5 Q 4}$ & $\mathbf{2 0 1 8 Q 2}$ \\
\hline Aggregate Demand AD (Tab 22) & $21,520,918$ & $22,832,653$ \\
\hline Aggregate Supply AS (Tab 22) & $17,456,225$ & $18,511,576$ \\
\hline GDP Deflator Index (Tab 40) & 105.06 & 110.172 \\
\hline$\Delta$ GDP Deflator & & 5.112 \\
\hline Excess Demand in 2015 Q4 & $4,064,693$ & \\
\hline
\end{tabular}

\section{OBSERVATIONS ON BRINGING THE E-BOOK'S INNOVATIVE PEDAGOGIC APPROACH INTO THE CLASSROOM}

At the end of the day, the focus should be on whether the templates are a valuable teaching device and a pragmatic tool kit that can be used effectively by students. This may be a decisive selling point, especially for instructors whose students may want to continue on in their study of economics and business at the intermediate and advanced levels. In all instances, we believe that the answer to the utility question is "yes". There is a track record: we have experimented with this approach in the classroom since the Spring of 2016; compiled the findings; and can now report on the lessons learned. The latter have been distilled into a set of proven action items.

Necessarily, the standard for reaching a judgement about the value of this project is whether students have acquired retainable macroeconomic literacy and developed real economic intuition. By following the procedures outlined below, there is a good chance of attaining this goal.

The routines that determine whether goal attainment is likely to occur ultimately depend on managing the size of the student workload, and on instituting monitoring and incentivizing activities. In my experience, the following activities have proved useful:

1. At the beginning of the semester, I divide the class into teams (at Towson, the goal is to create groups containing approximately 5 students, including a leader/facilitator). This step is 
intended to seed the creation of a learning environment which encourages internal deliberations and promotes sharing of the work load based upon skill sets and interests.

2. Each team is assigned the task of updating the core templates (I, IIA.1, IIA.2 and IV) and submitting its numerical estimates and written findings for a grade. The updating cycle occurs twice over the semester, and accounts for $20 \%$ of the final GPA. As I grade the submissions, I develop a keen sense of what material has been mastered and what hasn't been.

3. Concurrently, there are three one hour labs that I conduct for those students who want guidance on general Excel operations, or on specific instructions for managing templates routines. Feedback in this environment usually uncovers further areas where student mastery may be incomplete. These issues are then addressed in class directly, or in subsequent revisions to the text and master Excel file.

4. When the semester ends, students are confronted with an essay question on the final exam which asks them to analyze a mainstream media article devoted to the macro economy. Their analysis must be based upon using the templates, summaries of which are provided in the test booklet. Since students become aware of this requirement during the first week of class, the challenge of an "article" test question never comes as a surprise. Moreover the media article ultimately chosen is not a misdirection or a trick. It resides in a test pool, along with 25 other candidates, that hide in plain sight on my blackboard page. So, reading the "uploads" pays off when it comes to the final.

5. In general, having students cultivate the study habit of scanning the press should be deliberately encouraged. Towards this end, during the semester, I routinely comment on media items that I've found interesting, and indicate where this type of information can be obtained, free of charge but subject to low usage downloading. All of my uploaded "blackboard" media items are culled from the many offerings found on a host of respected public websites including: Reuters, CNN, Bloomberg, the New York Times and the Washington Post. Because students are encouraged to keep up with these articles, some classroom time is deliberately set aside for dissecting the published arguments and for relating them to currently assigned chapters in the textbook (both "Principles" and e-book). Finally, to guide this type of practical learning, there is a section in the e-book devoted specifically to conducting media analysis. This portion of the e-book is discussed in class, and used as a template for practicing the analysis on past semester blackboard uploads.

6. Since the approach described is "group" oriented, there must be a mechanism for discouraging "free riders." Group leaders are asked to monitor team member participation, in real time, and report what is occurring. If needed, I inform potential "free riders" that the assignment is mandatory, and failure to be a team player will result in expulsion from the group. If warnings are neglected, non-participants are told they must submit the homework assignments on their own without the benefit of group input.

7. To further incentivize commitment, a reward is given to individual student effort. Successful completion of Templates III,V and VI.1 will raise the base line group grade (B), that all members receive, to an "A" for the student making the extra effort.

8. Scheduling the assignments in the e-book and excel file is critical for managing student work load. My approach may appear to be somewhat rigid/ overly prescribed, and individual instructors may want to develop their own routines. Nevertheless, this is how I proceed. I introduce the e-book in the first week of class and assign Section 1 and video 1. Students are expected to do the assignments casually as homework over the next three weeks and should prepare to spend a few hours becoming familiarized. After the first mid-term test, the macro models are looked at in depth and the effort becomes tightly focused. Over the course of the next 4 weeks, the theoretical AE and ADAS templates, and their instantiation as empirical models, are assigned. During the month, 4 chapters in the "Principles" text and 5 sections in the e-book are explored. Studying the e-book, excel files, and instructional videos 2-6 will probably require up to 10 hours of student effort. 
To get acceptable results, I rely on monitoring, through labs and submissions, and provide the necessary value incentives along the way. In my classes, the essay question is worth $20 \%$ of the final exam grade, and this contribution along with the group project submission means that macro modeling accounts for almost $30 \%$ of the final course grade. The use of successful pedagogical techniques is also in play: interactive learning, grounded in data acquisition methods and mastery of a few elements in the Excel software works to promote retention of key macroeconomic concepts. This type of engagement goes well beyond what is learned by simply reading a basic text book, mining a test bank, drilling with flash cards or doing contrived analytical exercises.

Of course, it is ultimately the positive feedback actually received from the groups that confirms the project's proof of concept and its usefulness.

\section{ARTICLE OVERVIEW}

This article will attempt to summarize the key empirical findings and the most important steps in the methodological approach discussed in the e-book. In effect, the templates described below are a pragmatic tool kit for doing qualitative analysis of macroeconomic trends. The structure of these comments is oriented around the presentation that I made at the May 2019 Ninth Annual Conference on Teaching and Research in Economic Education (CTREE). The conference was sponsored by: the American Economic Association, the Journal of Economic Education, and the Federal Reserve Bank of St. Louis.

While the latest theoretical developments are not included in this book, the presentation, outlined below, of standard macro theory in a simple, up-to date, and empirically relevant format, is new. The discussion here highlights a virtually self- contained methodology for gathering the most recent data and for deploying this information in a set of 10 arithmetic templates which implement the Aggregate Expenditure and the Aggregate Demand-Aggregate Supply models. These templates have been used in the classroom; debugged; and revised in response to student input over the past three years.

From the start of this project, it has been my goal to create a simple device, i.e. a set of spreadsheet calculations, which students could use to monitor and evaluate trends in the level of GDP and aggregate prices. I think I've succeeded in this respect. Importantly, the resulting tool kit is both portable (i.e. downloadable) and updatable. Those students who want to retain a high level of macroeconomic literacy as they proceed in their education past their introductory courses can do soon at their own pace once they've read the book and mastered a few minimal spreadsheet operations. To reassure all concerned parties, the approach I have developed requires no prior knowledge of Excel or statistics. The calculation burden is not great: all formulae are arithmetic and embedded in the templates. Starting with data retrieval from the relevant agency websites and then porting this information to the templates, the whole process will ultimately take under five hours for the typical student to update the four core templates: I, IIA.1, IIA.2 and IV.

As a result of working through the templates, students will acquire the following skills:

1. Capability to perform "bare bones" spreadsheet operations.

2. Familiarization with essential NIPA data and its sourcing.

3. Knowledge of the procedures for implementing empirical macroeconomic theory: estimating critical variables and applying simple decision rules for interpreting macroeconomic trends.

4. Knowledge of the methods for using the templates to evaluate economic reports found in the main stream media.

5. Knowledge of the methods for using the templates to conduct hypothetical policy analysis.

\section{SECTION I: THE THEORETICALLY INSPIRED EMPIRICAL TEMPLATES: OVERVIEW}

Over the past 80 years, the study of aggregate economic phenomena has spun off several significant schools of thought. We do not address all of these different perspectives in my e-book or in this article. But this is by no means an indictment of the different findings and methods. We believe, for instance, that 
an exploration of "rational expectations," or "real business cycle theories" etc.is important, but beyond the scope of an "Introduction..." such as this e-book is. These topics are significant and more effectively dealt with in courses at the intermediate or advanced levels. In this article, we simply summarize the methodological approach and findings of the dominant school rooted in the Keynesian revolution.

Much of main stream macroeconomic modeling begins with Keynes' General Theory of Employment, Interest and Money. That book, and its codification by his American proselytizers including Paul Samuelson, Alvin Hansen and Lawrence Klein, sets the stage for the first template discussed here: the Aggregate Expenditure (AE) Model (Tab 2) explanation for the level of GDP. This is a fundamental building block. Completion of the AE Template provides critical output (the multiplier and the Balance of Injections and Leakages: "B/GDP") that is used in the subsequent Aggregate Demand-Aggregate Supply (ADAS) models. These extensions are covered in Templates IIA.1 (Tabs 21\& 22, Aggregate Price Level), IIA.2 (Tabs 23- 24b, Inflation Rate), IIB (Tab 26 Aggregate Price Level with monetary factors), and IIC (Tab 28 ADAS models with monetary factors and interest rates).

At the outset of the exercises, the AE analyses, including both the multiplier and "B/GDP" calculations, are first conducted in nominal dollars (Tab 2) and then repeated in constant dollars (Tab 102). Next, the analysis proceeds, from both price perspectives, to the generic ADAS models (Tabs 21 $24 \mathrm{~b}$, and Tab 105-107) ${ }^{6}$. Finally, toward the end of the Excel file (especially Tabs $113-139$ ), the AE and ADAS models are further extended to the most general case where the international sector is defined more broadly as the "Balance on Current Account" rather than the narrower "Balance of Merchandise Trade and Services", the latter which excludes net foreign factor income.

The ADAS models in the Excel master file focus on explaining the level of prices and their rate of growth. Obviously, while output determination is also a part of the general framework, this topic has been left implicit and relegated to the background. The textbook examples and templates are largely one sided, and concentrate on the price dynamics which originate from changes in aggregate demand. Model mechanics make this happens because the origins of the latter have been effectively imported from the AE models themselves. Justification for taking this approach is not hard to find. Since recent history (from 2009 on) has been one of almost uninterrupted output expansion, detailed discussion of AS output trends is not critical. But historical AS explanations, like the one covering the OPEC embargo episode, have not been analyzed here because, until now, they have been fairly uncommon. Going forward, such rare occurrences will probably become more typical. We suspect that fuller treatment of AS, beyond the "shifters" in Template III, may need to be covered in future editions of the textbook, especially as disruptions in the resource markets (oil) reemerge; climate change continues to damage US and global agriculture; and trade tensions potentially spill over disruptively into intermediate materials supply chains.

One may wonder why aggregate price levels command our attention as much as they do because the professional economics community (especially the FED) seems far more interested in the rate of inflation. First, policy makers do consider the expansion of real GDP and the level of real GDP per capita when taking stock of overall economic performance. Even though many believe that the comprehensive assessment of "well-being" must go beyond these two measurements, any credible metric must nevertheless include them. ${ }^{7}$ Therefore, calculating the GDP deflator is unavoidable. Second, it would be very difficult, if not impossible, to account for the growth rate of a price level when the latter's core calculation assumes there is a plausible, verifiable explanation for price levels at the outset ${ }^{8}$

To preserve copyright protections, the screen shots below are limited to the structure of the macro model operating on hypothetical data; its critical decision variables; and tests of model validity. Color coding is employed to make these findings easy to locate and interpret. The decision variable is highlighted in "blue:" and the model sign consistency tests are highlighted in "orange/gold" In all instances, numerical estimates are ultimately reduced to and evaluated in terms of their arithmetic sign. So model results should be seen as "qualitative" not precise quantitative measurements. 


\section{SECTION II: THE SPECIFIC AE MODEL TEMPLATES}

The commentary in this and subsequent sections will make liberal reference to the e-book text and the accompanying master Excel file. All estimates are keyed to the latest update of this file labeled: "July 2, 2019 Final Q1." Actual analogues to the hypothetical screen shots are located in the master file based on the tab number citations.

\section{Hypothetical Template Screenshots: AE Models}

\section{FIGURE 7 \\ OUTPUT DETERMINATION AND THE AGGREGATE EXPENDITURE MODEL: NOMINAL DOLLARS (EXCEL FILE TAB 2)}

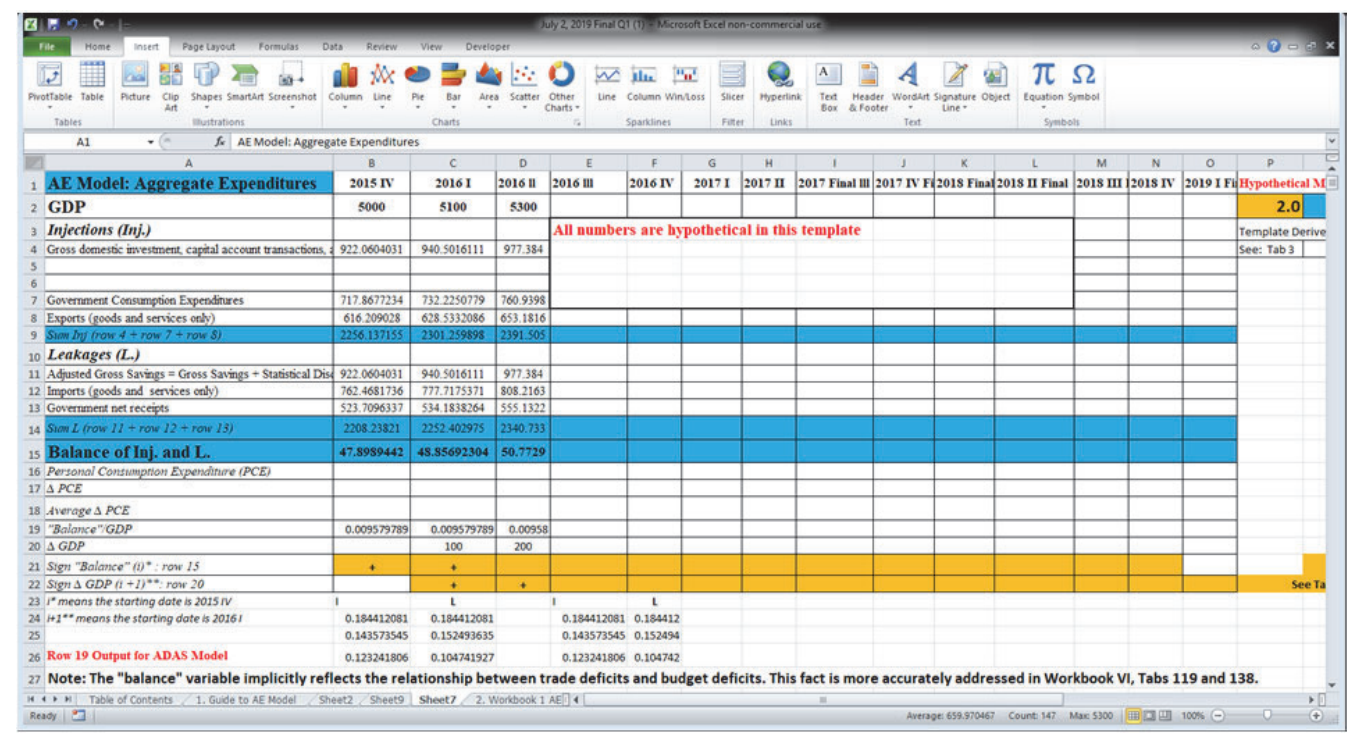

The actual data sets used to implement this template are found on the BEA website under tools/interactive data See: BEA Tables 1.5.5, 3.1 and 5.1

The above template explains the trajectory of GDP output. Assessment depends upon the arithmetic sign of the decision variable in row 15. More explicitly, model predictions are based on a simple rule for interpreting the "blue-shaded" decision variable:

1. The arithmetic sign (+ or -) of the "Balance of Injections and Leakages," regardless of numerical magnitude, governs whether GDP will grow, stay constant or contract. In the examples above the numerical values of the "Balance" are all positive which implies that the predicted change in GDP should also be positive.

2. Had the numbers been negative, contraction would be expected to follow.

Note the staggering of the "plus" signs in rows 21 and 22. Staggering is used because the "Balance" is an expenditure (stimulus) value calculated at the end of one quarter (say 12/31) which is then expected to exert its pent up influence on the level of GDP over the course of the subsequent time period beginning (say on 1/1). This "orange" stagger graphic is the model accuracy portion of the template which evaluates performance in terms of sign consistency. The comparison is based on the sign of the "Balance" in row 15 for one quarter (2015 Q4) as a predictor of GDP growth in row 19, $\Delta$ GDP, in the subsequent quarter (2016 Q1). In the above example, sign consistency is 100\%.Compare the alignment of cells B21 with C22 and C21 with D22. All relevant signs in the hypothetical example are + and highlighted in "orange." 


\section{FIGURE 8 \\ OUTPUT DETERMINATION AND THE AGGREGATE EXPENDITURE MODEL: CONSTANT DOLLARS (EXCEL FILE TAB 102)}

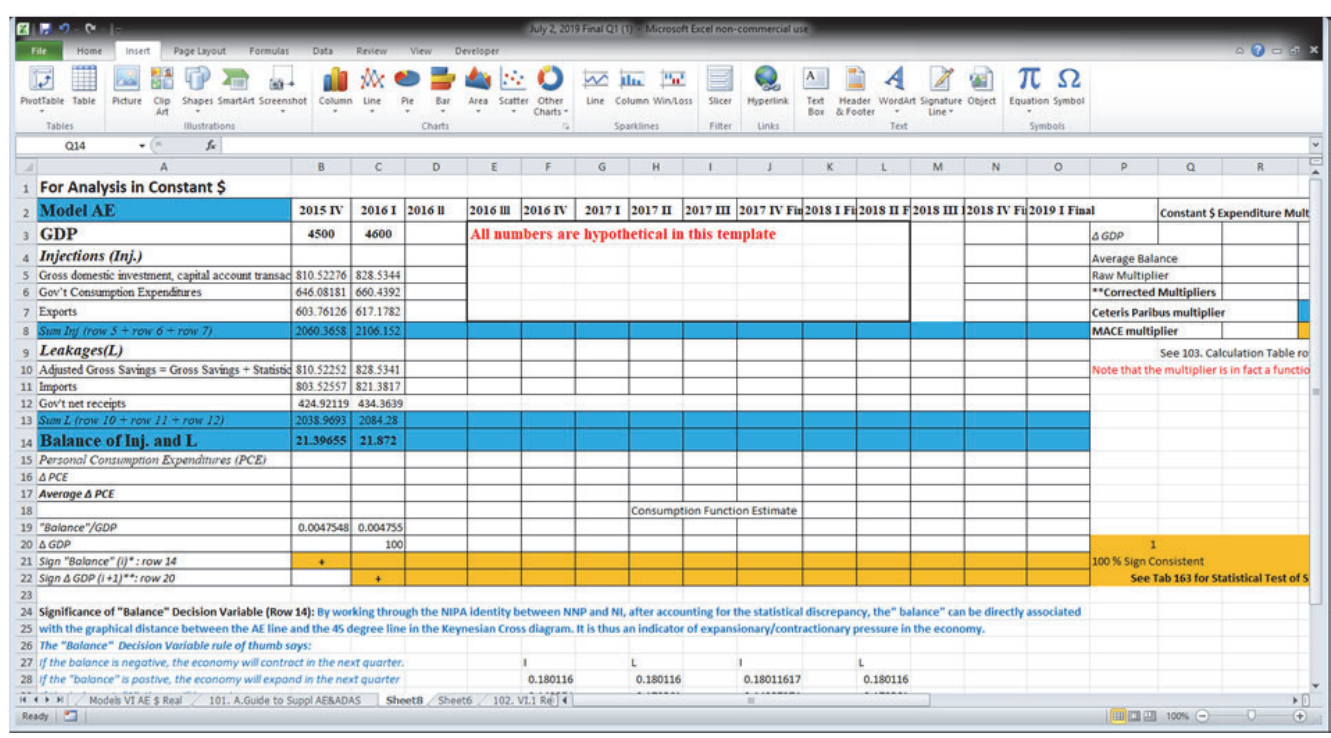

The actual data sets used to implement this template are found on the BEA website under tools/interactive data See: BEA Tables 3.1, 5.1, 1.5.5, 1.5.6, and 1.1.9.

\section{GENERAL DISCUSSION}

Both of these AE models have the following common features: 1) a critical decision variable (the balance of injections and leakages, found in rows 15 and 14 respectively and colored in "blue," 2) a sign consistency test colored in "orange/gold" found in rows 21 and 22;3) the "Balance" as a fraction of GDP (B/GDP , row 19) which is an input to the ADAS models, and 4) the multiplier estimates found in columns "P-R", which are also inputs to the ADAS models. It is important to stress that "blue shaded" "balance of injections and leakages" is a standard reference point for evaluating the model's theoretical equilibrium condition, and is found in many textbooks ${ }^{9}$.

Be aware that this "Balance" approach is a modified version of the more typical Keynesian "cross" diagram presentation. Consequently, the AE "Balance" needs a discussion which illustrates concordance with its more common sibling. This process can be visualized graphically where the "Balance" measures the vertical distance between the AE curve (where the consumption function is implied but not given explicitly) and the 45 degree line for any given level of GDP.

In effect, what is being done is simply incrementing the autonomous component of the original consumption function and parallel shifting it upwards by the amount of the autonomous shift in the "Balance." Thus the new equilibrium for the model must now be found graphically by identifying the subsequent intersection of the AE curve and the 45 degree line.

In our final comments about these models, we point out that Templates I (Tab 2) and VI.1 (Tab 102) do not address how all of the determinants which shift the consumption function, and hence the Aggregate Demand Curve, behave. The latter is the subject of Template III: Detailed ADAS Model. It is obvious that "PCE" is not a formal component of the equilibrium condition where $\mathrm{S}+\mathrm{M}+\mathrm{T}=\mathrm{I}+\mathrm{X}+\mathrm{G}$. Still, consumption is surely implicit. It is important to realize that, within the confines of the template, there is no mechanism (variable) for addressing how variations in wealth or consumer expectations affect the level of household spending. Nevertheless, changes in taxes and savings are accommodated indirectly through the leakages labelled "T" and "S", and they will ultimately affect consumption. 


\section{ESTIMATION OF THE MULTIPLIER ${ }^{10}$}

Since the multiplier is a key element of the ADAS models, some commentary is needed to elaborate and justify the algorithms used; the interpretation of the estimates proposed; and scope of the results examined.

The estimates for the multiplier in the hypothetical example below should be considered a first approximation to the autonomous expenditure representation of the concept. The framework is comparative static in nature; it is not a time series dynamic approach. Cross section budget studies are not utilized for determining the marginal propensity to consume. No allowance is made for a progressive tax structure or for the marginal propensity to import. And finally, the framework does not permit autonomous expenditures to adjust during the time period in which macro equilibrium in the instantaneous comparative statics AE model is re-established ${ }^{11}$.In short, the estimate best describes a situation in which the economy is stable; structural changes, if they occur at all, are happening slowly; and countercyclical monetary/fiscal policy is not being deployed.

Calculation is simple. The "uncorrected" method requires dividing the change in GDP over a one year period: 2017 I - 2016 I or (here assumed to be 600) by the average change in net expenditures associated with the "Annualized Balance" from the previous four quarters, 2016 I- 2016 IV, (here assumed to be 240). The multiplier in this case is 2.5. For the "ceteris paribus "measurement, the method requires dividing the same change in GDP (600), netting out the average consumption increases, (240), and then dividing the remainder (360) by the same average change in net expenditures (240) used in the uncorrected calculation." Here the hypothetical multiplier falls to 1.5. Finally there is an iterative estimate called the MACE which produces a value of $2.0^{12}$. Nevertheless, at 1.5 (and possibly as high as 2.5 ), we assert that he hypothetical magnitudes are broadly consistent with the best empirical evidence.

If we accept this asserted correspondence between our hypothetical estimates and the empirical record for the time being ${ }^{13}$, there is reason to believe that these multipliers will function as a pragmatic tool that can be reliably used in conjunction with the ADAS templates. In this latter capacity, the multiplier should be viewed as a "one period ahead" scalar. Thus "imbalances" in one quarter lead to expansion or contraction of GDP in the subsequent time period. However, because of its heuristic nature and nonrigorous derivation, it will probably need to be routinely updated, perhaps as often as every two years.

FIGURE 9

MULTIPLIER CALCULATION TABLE

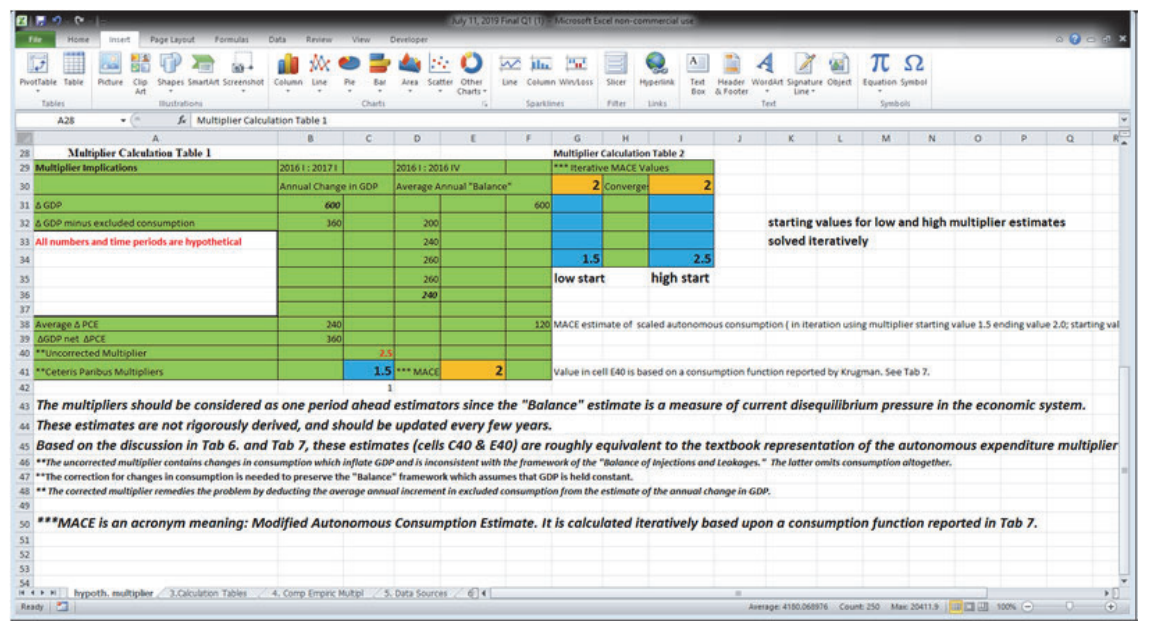

Journal of Applied Business and Economics Vol. 21(7) 2019125 


\section{RATIONALE FOR NETTING OUT $\triangle$ PCE}

Netting out $\triangle$ PCE is an attempt to preserve the comparative static framework of the "Balance" approach given that the actual data used in the analysis is time series in nature. To understand the need for this correction, there are 3 features of the "balance framework" that need to be stressed: 1) each "balance" is referenced to a unique, fixed level of GDP, 2) given basic NIPA accounting identities and subsequent simplifications, the actual "balance" winds up being measured without any term for consumption. The latter is in the background and assumed to be fixed by the consumption function for a specified level of GDP, and 3) the simple textbook multiplier is based on a parametric MPC, but in principle can be derived empirically by performing the above template calculations properly. Because the MPC is thought to be parametric, the simple multiplier is necessarily a constant. Therefore, the calculated "template" multipliers should also be considered parametric constants, and their algorithm should take this equivalence into account. In practice, this means that measurement of the multiplier scale factor should be based on principles that make it independent of any induced consumption which ensues with successive rounds of increasing output and income.

The above calculations are, in effect, saying that all of the quarterly data observations represent simultaneous/contemporaneous variations in the "balance" stimuli, and that the average of those stimulus variations collapses to a single datum and equals the actual, contemporaneous, level of total autonomous increases in expenditures. This can be visualized graphically where the "balance" measures the vertical distance between the AE curve (where the consumption function is implied but not given explicitly) and the 45 degree line for any given level of GDP. As mentioned towards the top of the previous page, one is simply incrementing the autonomous component of the original consumption function and parallel shifting it upwards by the amount of the autonomous shift in the "balance." Even though savings must always equal investment by definition ex-post, the initial equilibrium for the private closed economy AE model is not necessarily preserved when all modified injections and leakages are now included as in the mixed open economy case. This generalization permits us to model the expansion path of the economy.

Though it might seem otherwise, the modeled cumulative impact of the infusion of new "balances" into the expenditure stream does, and must, permit induced consumption spending along its equilibrium, time-independent, path. Otherwise the multiplier concept would be meaningless. However, this induced impact cannot be properly measured without first constraining each of the quarterly GDP observations to behave as if they too were contemporaneous alternatives, and that they too had been purged of any increments to consumption which arose because we were dealing with values of measured GDP which had expanded over time. Otherwise, one faces the tautological situation where unpurged or residual "induced consumption" is being used to explain "induced consumption." On closer inspection, one can also see that implied "foreign lending" (i.e. negative net exports) is supporting current levels of investment and government deficit spending. Neither of these components of aggregate expenditure is an initial consequence of changing personal consumption expenditures.

\section{SECTION III: THE SPECIFIC ADAS MODEL TEMPLATES}

\section{Determining the Aggregate Price Level Using the Basic ADAS Model (Excel File Template IIA.1, TAB 21}

The first models in Template II examine aggregate price levels (GDP deflator) based on the interaction of the Aggregate Demand (AD) and Aggregate Supply (AS) curves. The initial presentation is largely indirect, and hence inferential, since many of the measurements are based on "shifts" in AD and $\mathrm{AS}$, and not on the initial positions of the fully depicted underlying curves ${ }^{14}$. Interpretation of the subsequent model results is based on a priori reasoning: if the ratio of the demand shift (\% $\mathrm{AD})$ to the supply shift $(\% \Delta \mathrm{AS})$ is positive and greater than 1 , then whatever gap there is between actual AD and AS (i.e. excess aggregate demand) is widening ${ }^{15}$. As a result one would expect upward pressure on prices. The e-book text presents graphical analysis of this phenomenon on pp. 29 -34, including its Figures 7 and 8. 


\section{FIGURE 10 \\ AGGREGATE PRICE LEVEL (GDP DEFLATOR) DETERMINATION AND THE BASIC ADAS MODEL}

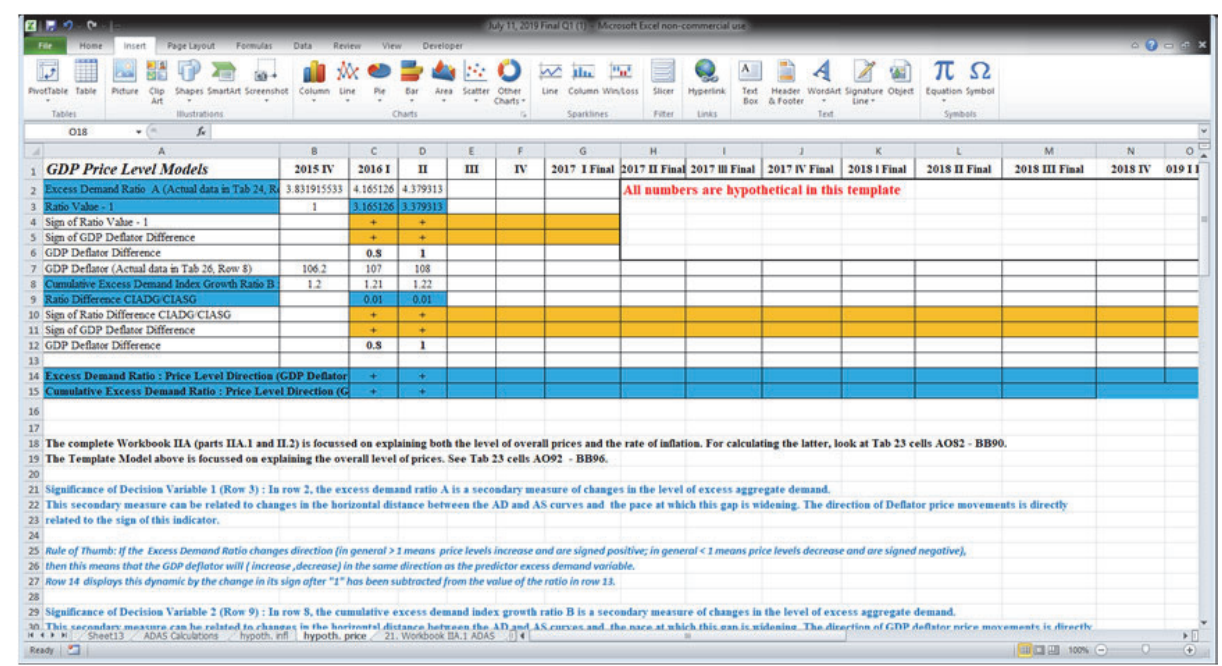

The actual data sets used to implement this template are found on the BEA website under tools/interactive data See: BEA Tables 1.1.2, 1.1.4, 1.1.5, 1.1.7.

In the example above, the first excess demand decision variable (row 3) has values that are all $>1$ and therefore assigned + signs, while the changes in the GDP deflator (row 6) are all likewise $>0$ and therefore assigned + signs. Correspondence is therefore $100 \%{ }^{16}$.

The second price model views the determination of the GDP deflator in terms of the cumulative level of $\mathrm{AD}$ vis-a-vis cumulative AS. This model variant is an important alternative because it allows us to unify the entire presentation of ADAS dynamics when capacity constraints and monetary factors are included in the framework. ${ }^{17}$ This approach also provides a method for evaluating the causes of the steady monotonic rise in the aggregate GDP price deflator over the last $4+$ decades $^{18}$. Finally the presence of monetary factors in the broader framework will later suggest a mechanism for examining monetary policy initiatives. ${ }^{19}$ Quarterly growth rates of AD are reported in Tab $22 .{ }^{20}$ Details on the construction of this variable can be recovered by clicking on any relevant cell in Tab 22, row 81, and examining the algorithm found in the formula bar for cumulating the estimates. The conversion of the cumulative growth indices into actual dollar values of GDP is based on using the initial value of the series, taken as "1," and scaling it with measured GDP (either AD or AS). We identify AD with measured GDP minus inventory change (designated as: FSDP: final sales of domestic product) since this is how much was actually sold. We identify AS with measured GDP since it reports how much was actually produced in the domestic economy. In this way, the entire time series of growth rates is recovered and ultimately converted to dollars. In parallel fashion, inspection of the second price model in the template follows the same procedures applied in the first price model instance: the hypothetical direction of price movements is thought to be governed by the sign of the decision variable in row 9, and model evaluation, in terms of hypothetical sign consistency, is displayed in rows 10 and 11. 


\section{Determining the Rate of Inflation Using the Basic ADAS Model (Excel File Template IIA.2, TAB}

23)

The analysis of inflation builds on the first price model by examining the rate of change of the GDP deflator and its relation to the percentage change in the above predictor variable for the level of the aggregate GDP deflator. This is a mathematically symmetric treatment because rates of change are being related to rates of change.

\section{FIGURE 11 \\ RATE OF INFLATION (PERCENTAGE CHANGE OF GDP DEFLATOR) AND THE BASIC ADAS MODEL}

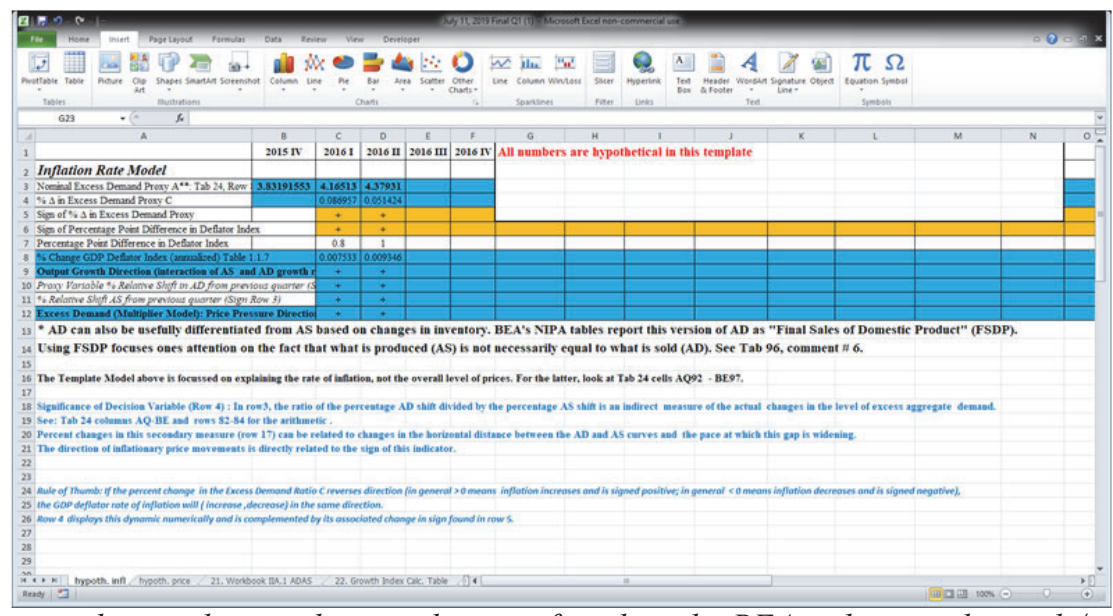

The actual data sets used to implement this template are found on the BEA website under tools/interactive data See: BEA Tables 1.1.2, 1.1.4, 1.1.5, 1.1.7.

The decision rule for the inflation rates model is very similar to the standard proposed for price model 1 . But now it is the percent change in the excess demand ratio $(+,-)$ that governs the direction of inflation rates. Values of the \% change in the "excess demand" ratio greater than zero imply increasing rates of inflation. Conversely, values less than zero imply falling rates of inflation.

The underlying calculation table supporting the first price model and the generic inflation model is shown below. It is a facsimile of the actual tables found in the master Excel file on Tabs 24, 24a and 24b.

FIGURE12

A COMMON HYPOTHETICAL ADAS CALCULATION TABLE

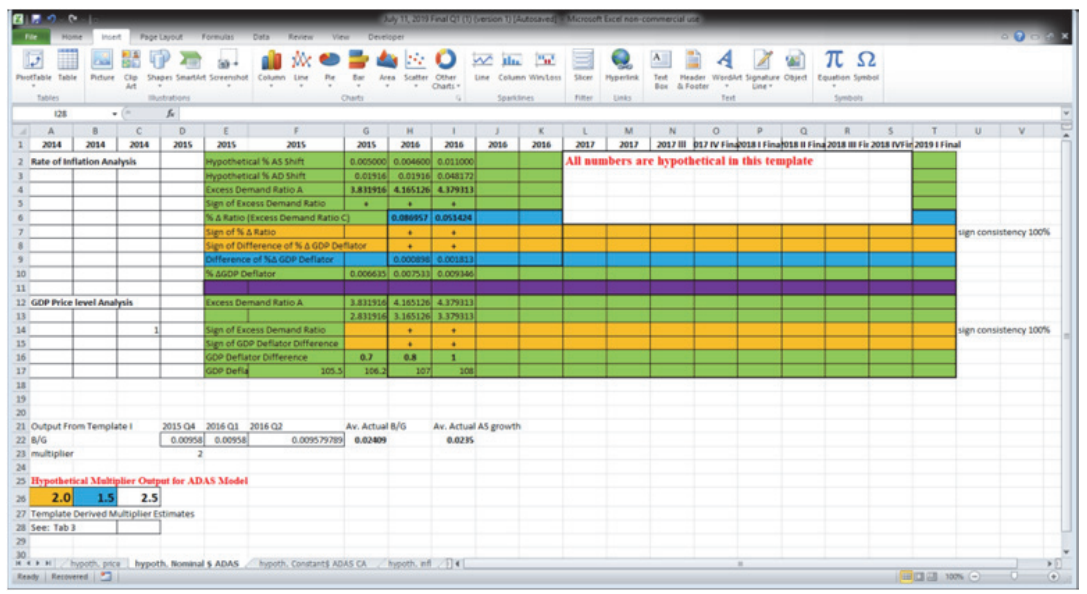

128 Journal of Applied Business and Economics Vol. 21(7) 2019 


\section{Determining Aggregate Price Level 21 Using Monetary Variables and Excess Demand (Excel File Template IIB, TAB 26)}

The previous models used "excess demand" in isolation to explain aggregate price levels. Additional insight about price levels may also be provided within the context of simple monetary theory using the so called "equation of exchange": where $\mathrm{M}^{*} \mathrm{~V}=\mathrm{P}^{*} \mathrm{Q}$. The empirical justification for this approach is found on Tab 26 in the summary regression statistics profile below the "write up" section. It is also found on Tab 169 along with the data set used to perform the regression experiments. The template below reports the combined impact of using excess demand and monetary decision variables. It then inspects their respective arithmetic signs for a consistent relationship with movement of the GDP deflator. In this hypothetical example, the two independent decision variables line up perfectly with changes in the GDP deflator. Sign consistency is therefore $100 \%$.

\section{FIGURE 13 \\ AGGREGATE PRICE LEVELS IN THE PRESENCE OF MONETARY VARIABLES AND EXCESS DEMAND (EXCEL FILE TEMPLATE IIB, TAB 26)}

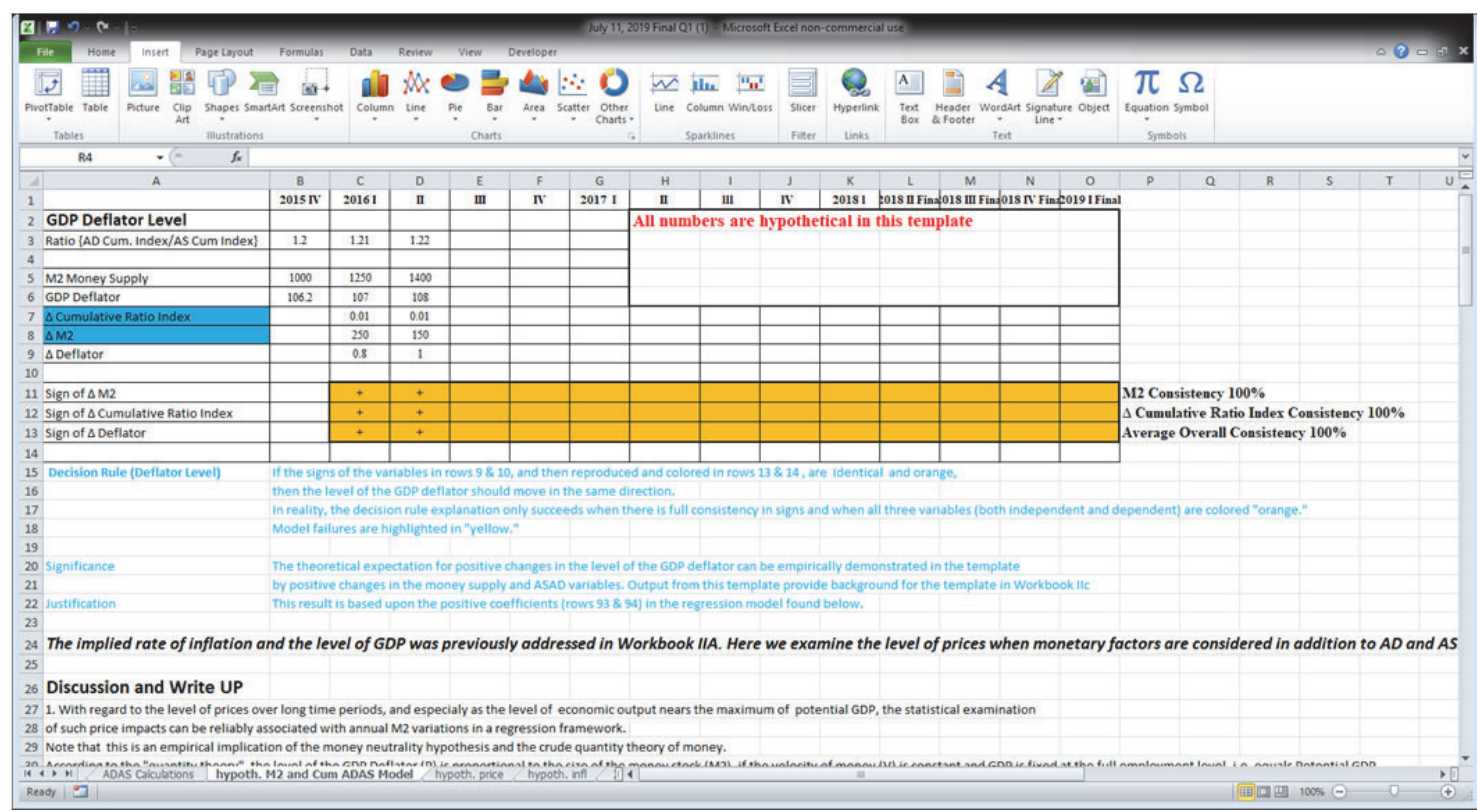

The actual data sets used to implement this template are found on the BEA website under tools/interactive data. Besides the previous BEA Tables 1.1.2, 1.1.4, 1.1.5, 1.1.7, see the FRED variable with the ID label "M2" (M2 money stock).

\section{Determining Interest Rates and Investment Using Monetary Variables and Excess Demand (Excel File Template IIC, TAB 28)}

The comments offered here are general. They suggest some of the structure of the "Cambridge School" (Harvard/MIT) synthesis of monetary theory within a Keynesian framework. But the model portrayed below is not completely formalized or quantified ${ }^{22}$. Nevertheless, the remaining shell, without the data and calculations, is still a useful framework for organizing future empirical investigations. The framework clearly outlines the chains of causality linking the interaction of money demand and money supply to the interest rate, and then relates the interest rate to investment. But for the time being, the ultimate payoff remains uncertain and incomplete as long as this template fails to be a fully functional tool. To have the latter, it will be necessary to quantify the combined impact of the transactions $\left(\mathrm{M}^{\mathrm{t}}\right)$ and asset $\left(\mathrm{M}^{\mathrm{a}}\right)$ components of monetary demand, and then specify how the level of interest rates affects investment in the presence of changes in the level of aggregate economic activity (GDP). It will also be 
necessary to distill these modifications into a set of simple arithmetic excel spreadsheets with common sense decision rules. Three modules are employed to explain the template:

\section{FIGURE14 SHELL MODULE 1}

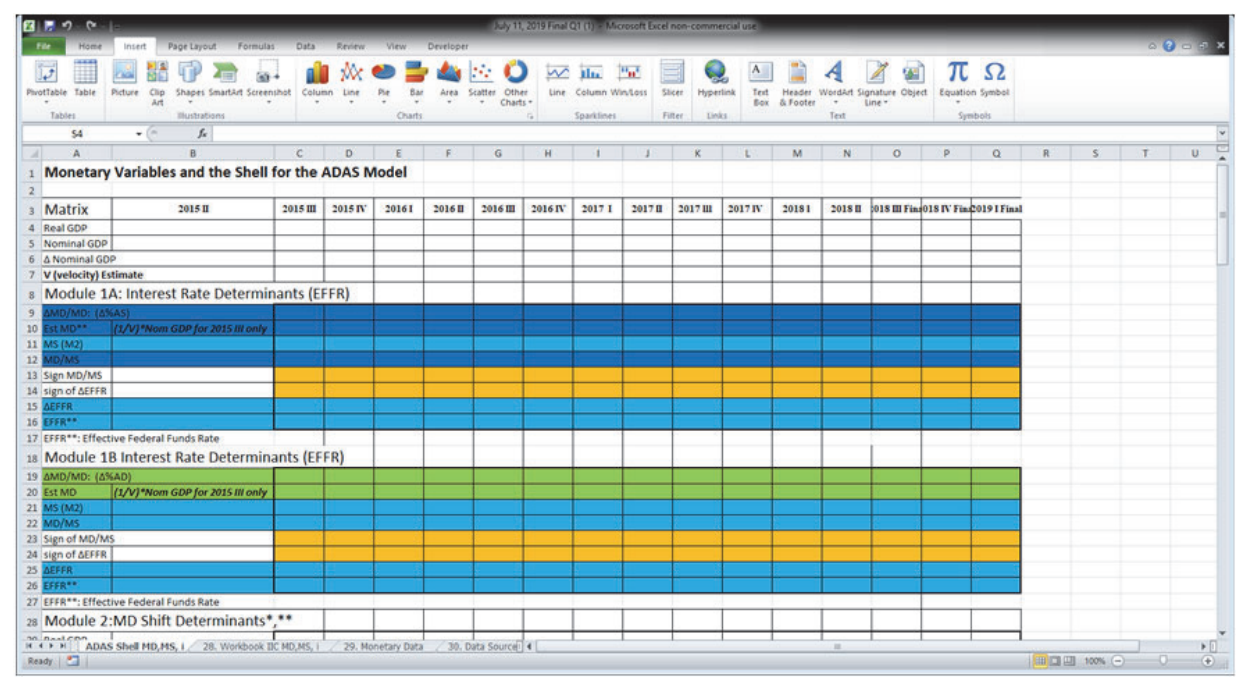

FIGURE 15

SHELL MODULES 2 AND 3

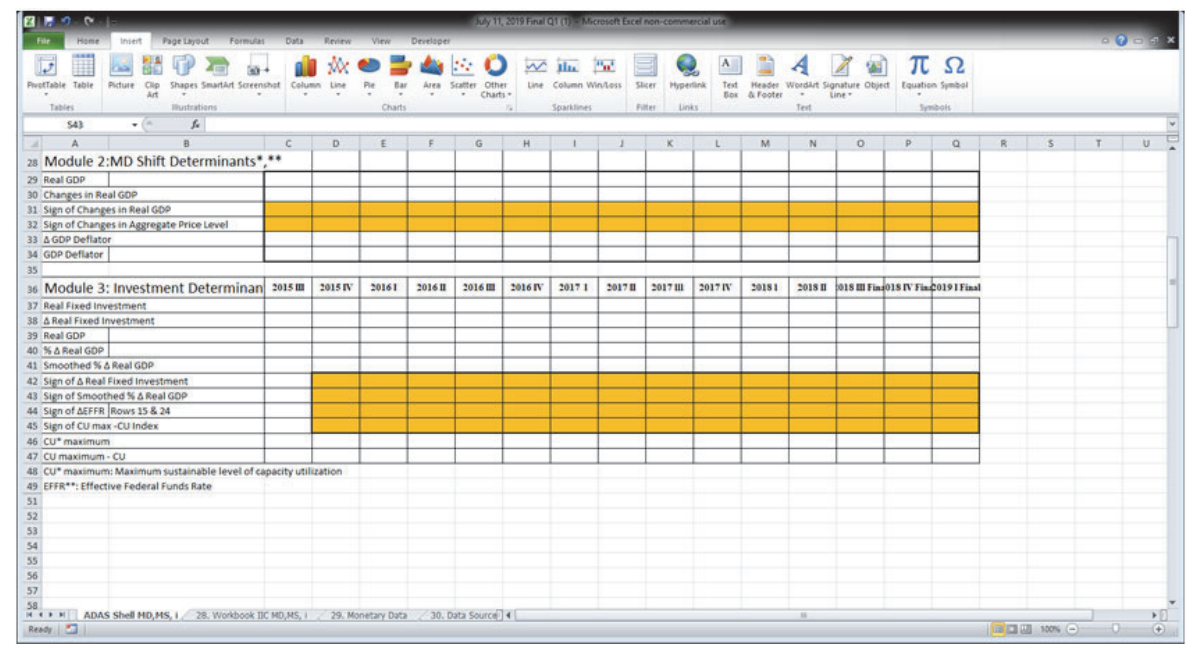

The actual data sets used to implement this template are found on the BEA website under tools/interactive data. Besides the previous BEA Tables 1.1.2, 1.1.4, 1.1.5, 1.1.7, see the FRED variables with the ID labels "M2" (M2 money stock) and "EFFR (Effective Federal Funds Rate).

\section{SECTION IV: SUPPLEMENTAL ADAS AND AE MODEL TEMPLATES}

\section{Hypothetical Template Screenshots: Supplemental ADAS and AE Models}

The previous ADAS models focused on output and price dynamics without examining the specific reasons why the AD or AS curves might shift. Nor was there any discussion of the extent to which the level of GDP was pressing up against capacity constraints, and thus approaching the limits of sustainable output. Template III (Tab 45.Detailed Aggregate Demand-Aggregate Supply Model) deals with the former question and inspects a large sample of the most important shift "determinants" for both AD and 
AS. Template IV (Tab 67 the Simplified Capacity Model) considers the latter issue, and analyzes the "verticality" (slope) of the AS curve.

This first template is less analytic then models encountered to this point in the overview. Simple growth rates of the shift variables are calculated and then related to the direction that the relevant AD or AS curve moves. No sign consistency tests are employed. Instead the reader is asked to compile a summary list, for both $\mathrm{AS}$ and $\mathrm{AD}$, of the respective shift variables that move right and those that move left, and then to do a simple count of those falling into either category. This paints a general portrait of what is going on.

In the hypothetical example below 8 of the 9 AS "determinants" shift AS left, and 1 shifts it to the right. Note that the critical average productivity of labor produces rightward movement, while the critical employment cost index counteracts this dynamic and corresponds to leftward movement.

For the AD curve determinants, the University of Michigan's "Index of Consumer Sentiment" and the "Index of Consumer Expectations" are important barometers of household spending going forward. Also, one should pay particular attention to the variables numbered 16-19. Those labeled "New Orders" are dollar volume leading indicators of consumption and investment expenditures that will be completed in the near future.

\section{FIGURE 16}

\section{TEMPLATE III: DETAILED AD AND AS SHIFT PARAMETERS (EXCEL FILE TAB 45)}

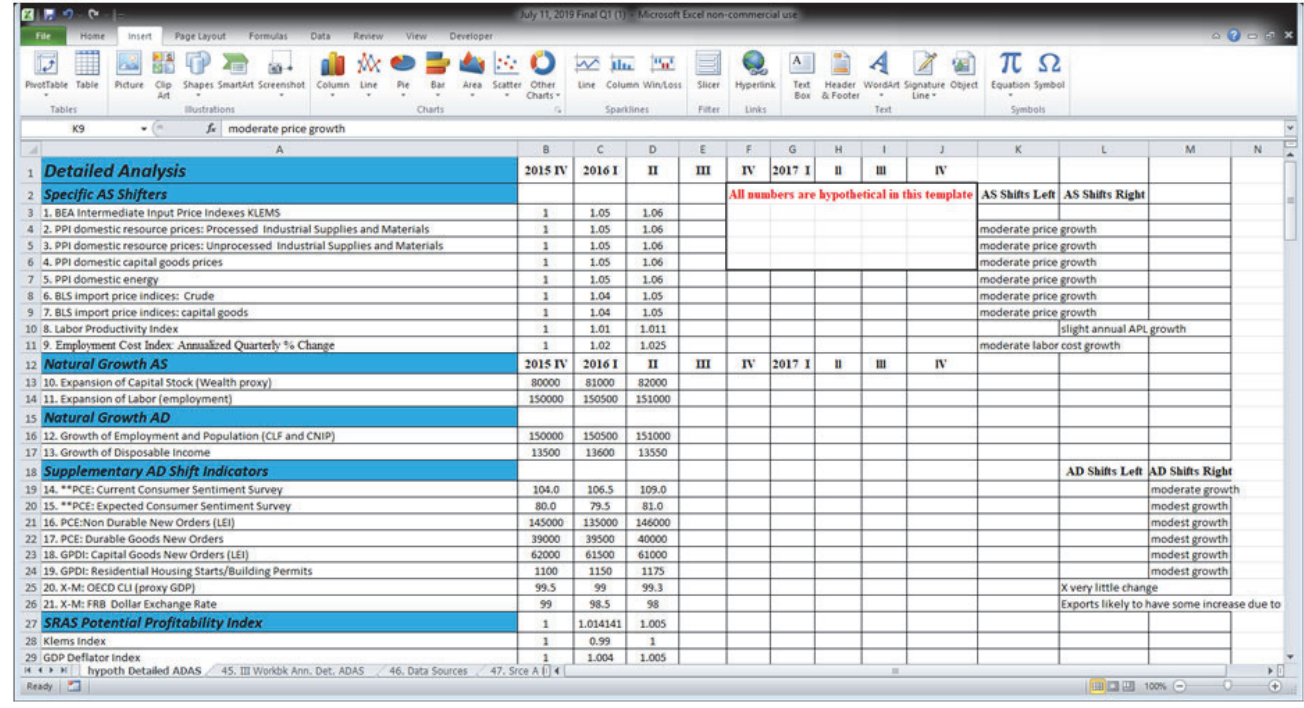

Data Sources:

1. KLEMS price indexes (BEA GDP-by-Industry Tab: Table Chain-Type Price Indexes for Intermediate Inputs by Industry)

2. Changes in Net Stock of Produced Assets (Fixed Assets and Inventories) Annual (BEA National Data Tab Table 5.10)

3. Real Disposable Personal Income Aggregated to Quarterly Values (FRED/Census: DSPIC96)

4. Housing Starts (FRED/Census HOUST)

5. Manufacturers' New Orders for Durable Consumer Goods -aggregated to quarterly values (FRED/Census: ACDGNO)

6. Manufacturers' New Order for Capital Goods- aggregated to quarterly values (FRED/Census: ACTGNO)

7. Producer Price Index by Commodity for Final Demand: Energy - aggregated to quarterly values (FRED/BLS: PPIDES)

8. Producer Price Index for Intermediate Demand by Commodity Type: Unprocessed Goods - 
(FRED/BLS: WPUID62)

9. Producer Price Index for Intermediate Demand by Commodity Type: Processed Goods - (FRED/BLS: WPUID61)

10. Producer Price Index-Capital Goods (FRED/BLS WPSFD49215)

11. Civilian Employment Level - aggregated to quarterly values (FRED/BLS: CE16OV)

12. Import Price Index-Industrial Supply and Materials (FRED/BLS IR1)

13. Import Price Indexes-Iron and Steel, Crude and Capital Goods (FRED/BLS: IR, IR141,IR2,IP2709, IR10000)

14. Trade Weighted U.S. Dollar Index: Broad - aggregated to quarterly values (FRED: TWEXBMTH)

15. OECD Composite Leading Indicators (CLI) Proxy for GDP (OECD: www.oecd.org/std/cli)

16. Current Consumer Sentiment Survey: www.sca.isr.umich.edu

17. Expected Consumer Sentiment Survey: www.sca.isr.umich.edu

Template IV addresses whether economic output is approaching non-sustainable levels. Measurements here have important implications for the level of aggregate prices and the rate at which they increase. There are two measures for assessing whether the AS curve has become nearly vertical: the first involves a comparison of the actual rate of unemployment to the "natural rate of unemployment"; the second compares actual levels of GDP to "potential" GDP.

\section{FIGURE 17}

\section{TEMPLATE IV: SLOPE OF AS AND PROXIMITY TO FULL EMPLOYMENT/POTENTIAL OUTPUT CONSTRAINT (EXCEL FILE TAB 67)}

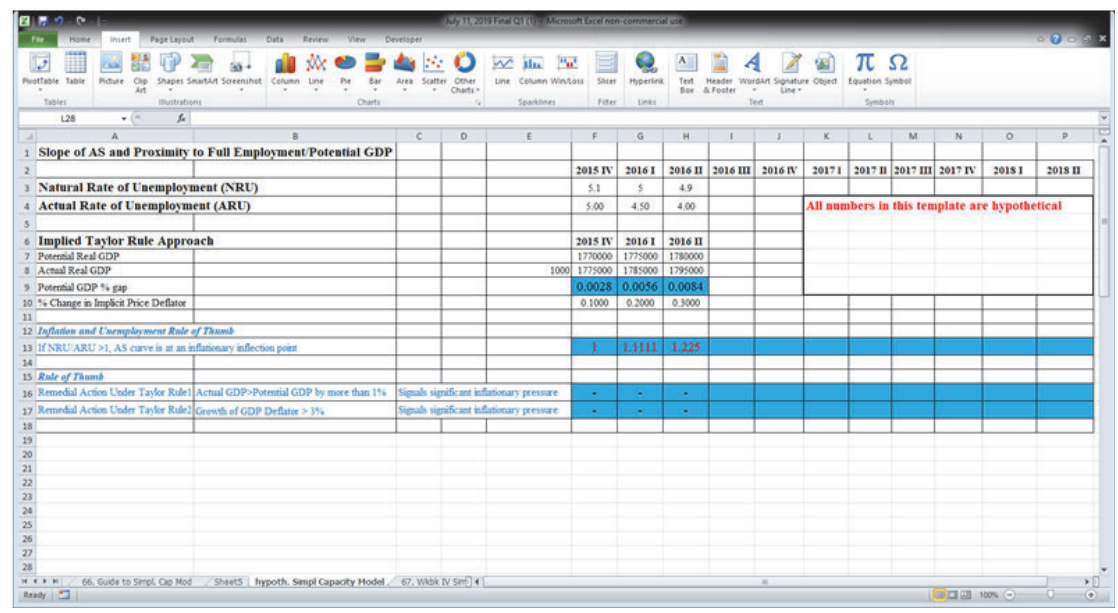

Data Sources: FRED/Congressional Budget Office CBO: NROU; FRED/BLS: UNRATE; FRED/CBO: GDPPOT; BEA Table 1.1.6

In this hypothetical example, both measures of the capacity constraint signal, in tandem, that the economy has entered the vertical portion of the AS curve. Based on the actual data in the master Excel file, there is significant statistical regression justification for the inference (see: Tabs 166 and 169). Specifically, the level of the price deflator is explained by: 1) the difference in the natural rate of unemployment minus the actual rate of unemployment in isolation; 2) the difference in the natural rate of unemployment minus the actual rate of unemployment plus an excess demand variable (cumulative $\mathrm{AD}$ /cumulative $\mathrm{AS}$ ); and 3) the difference in the natural rate of unemployment minus the actual rate of unemployment plus an excess demand variable (cumulative $\mathrm{AD} /$ cumulative $\mathrm{AS}$ ) plus the M2 money stock. The implications of these findings have been drawn out in the model assessment section at the beginning of the review. 


\section{SECTION V: THE AE MODEL FROM AN EXPANDED INTERNATIONAL PERSPECTIVE}

\section{Hypothetical Template Screenshots of the AE Model from an Expanded International Perspective}

Both of the previously discussed AE and ADAS models have important counterparts, the first of which is displayed below. In this case, the balance of trade on merchandise and services is replaced by the balance on "Current Account" (CA). NIPA accounting rules make it necessary to modify the previous templates because BEA's integrated- seven -account NIPA framework would not balance globally unless the expanded international perspective were adopted ${ }^{23}$. Specifically, the adjustment to our framework is based on the inclusion of net foreign factor income. But once these new flows are included, the relevant measure of economic output can no longer remain GDP and must be replaced by $\mathbf{G N P}^{\mathbf{2 4}}$. Conversion means that subsequent estimates of the multiplier and the "Balance"/GDP variable must also be revised. To cut down on redundancy with the earlier discussion, we display the hypothetical template for the Current Account (CA) AE model in constant dollars only. Again to avoid tedious duplication, there is no illustration of the multiplier calculations.

Beginning with the constant-dollar-current-account version of the AE model, inspection shows that the format is nearly identical to AE templates previously discussed. But note the scope of exports and imports has been widened to include: 1) all income receipts and payments to and from the ROW (rest of the world), and 2) the dollar amounts associated with all taxes and transfer to and from the ROW. Furthermore, the template now has two entries for the "corrected balances," one in row 13 and the other in row 22. From either the narrow or broad international perspective, the imbalance between "exports and imports" establishes the need for a reverse flow. At the bottom of Table 4.1, there is an addendum which accounts for this reverse flow, and demonstrates the expected identity between net lending (or borrowing) and the balance on current account ${ }^{25}$. It is worth reiterating an earlier comment, stating that there are theoretical conditions which promote the " $\mathrm{S}=\mathrm{I}$ " identity. In practice, this equivalency means taking the variable "net lending" (borrowing) variable; relabeling it as net capital inflow (NCI); adding this dollar amount to national savings; and then observing the equality with investment, broadly defined.

Finally, note that two variants of the "corrected balance" are reported. In the first instance, the inclusion of net foreign factor income, as a component of the CA balance, is there to preserve the NIPA definitions and accounting identities that must prevail for the system equilibrium to be measured consistently. ${ }^{26}$ As a thought experiment, in the second instance, net capital inflows (NCI) are eliminated from the "corrected balance" to gauge how removal of foreign lending support would alter the magnitude of the expenditure stimulus. This calculation sets a possible threshold for determining impacts that might arise if trial balloon legislation aimed at promoting "Fair and Reciprocal" trade were implemented. More will be said about these types of trade and budget initiatives in the next section of this article where policy analyses are sketched out using the templates. 


\section{FIGURE 18 \\ TEMPLATE VI.4 CONSTANT DOLLAR AE MODEL ON CURRENT ACCOUNT (EXCEL FILE TAB 117)}

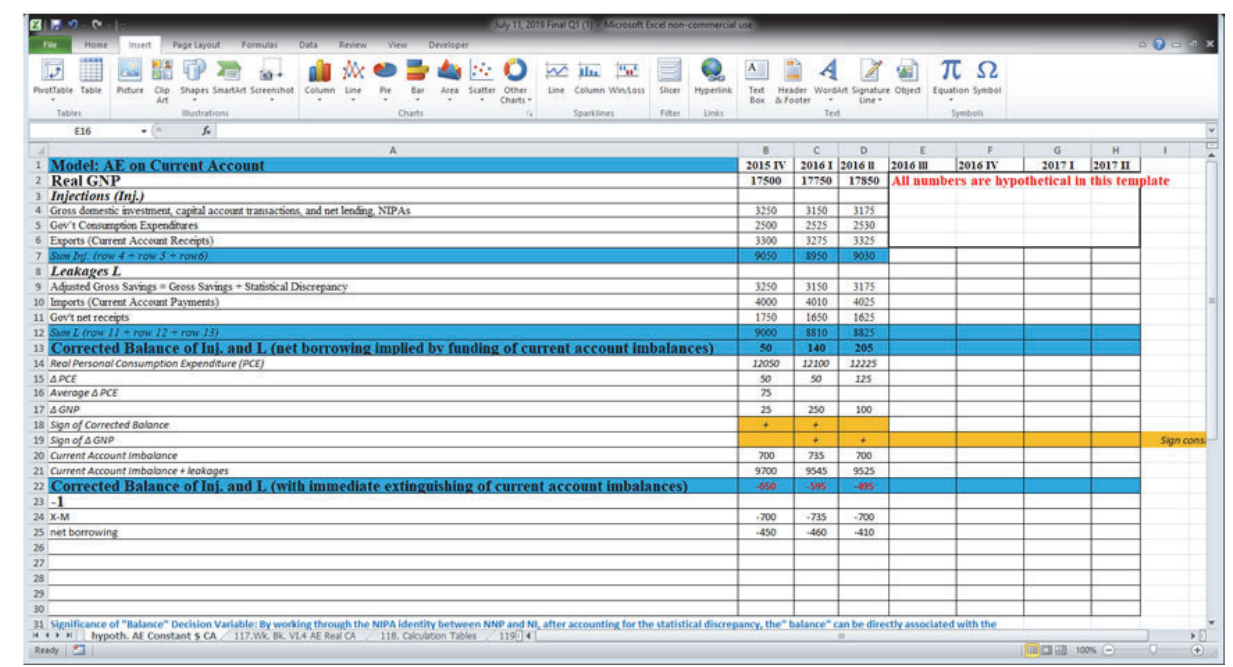

Data Sources: BEA Tables: 1.1.5, 1.1.7, 1.1.9, 1.5.5, 1.5.6, 1.7.5, 3.1, 4.1, 5.1.

The above template explains the trajectory of GNP output. Assessment depends upon the arithmetic sign of the decision variable in row 13. As in the non "Current Account" cases discussed on pp. 4-5 above, model predictions are based on the same simple rule for interpreting the "blue-shaded" decision variable.

Again, note the staggering of the "plus" signs in rows 18 and 19. Test accuracy of comparison is based on the sign of the "Balance" in row 13 for one quarter (2015 Q4) as a predictor of GNP growth in row 17, $\triangle$ GNP, in the subsequent quarter (2016 Q1). In the above example, hypothetical sign consistency is $100 \%$.Compare the alignment of cells B18 with $\mathrm{C} 19$ and $\mathrm{C} 18$ with D19. All relevant signs in the hypothetical example are + and highlighted in "orange." However, when the balance is calculated net of foreign lending, all of the signs become negative (row 22) and this would signal imminent contraction of GNP.

Concluding, being brief is a virtue. There is no additional insight to be gained here by constructing a companion hypothetical example of the ADAS model template, this time on CA, and then belaboring the reader with previously discussed identical and generic methods and finding.

\section{SECTION VI: AN EXAMPLE OF POLICY ANALYSIS}

The discussion which ensues is based on a limited, but representative, set of policy related tabs within the larger master Excel file. For reasons of space, not all of the issues touched on in the complete set of relevant spreadsheets (Tabs 144 -162) will be examined here. In the master file, there are attempts to illustrate how the "Balance of Injections and Leakages" can be transformed into a tool that quantifies impacts on both the level of GDP (Tabs 152-153) and on the GDP deflator and its rate of increase (Tabs 155-157, and 160). Hints of this first scenario were already included in the discussion above of the constant dollar AE model on current account (CA). Recapitulating, the reader is directed to row 22 in that template. Note that all estimates of the original corrected balance became negative and highlighted with "red" numbers once an implied, but unspecified, "legislative" scenario was adopted. The implication was that any policy which attempted to equate existing levels of exports and imports would result in unleashing contractionary expenditure stimuli, at least initially.

Building on that "teaser," the scenario is now revisited and expanded. The associated calculation tables explore how underlying NIPA accounting identities create a conceptual link between trade and 
budget balancing legislative initiatives. This linkage is then incorporated into the algorithms for quantifying the total output impact by summing the individual trade and budget components.

Since the calculations involved are quite detailed and numerous, we will only attempt to summarize their essence, and not get overly involved in the actual computations. Interested readers should turn to the e-book text on p. 75 for the full list of scenario caveats and pp. 80-81 for template procedures and manipulations. The arithmetic details of the computations are examined in Tabs 152,152a, and 153 .

Our scenario analysis requires using a simplified set of assumptions. Chief among them are:

1. Global supply chains are somehow not disrupted by the trade balancing legislation.

2. Countercyclical monetary/fiscal policy is not deployed to fend off possible contractionary pressures.

3. Dynamic feedback loops are not considered. The basic mechanism for quantifying impacts is the autonomous expenditure multiplier.

Interpretation of the policy template depends on the sign of the estimates in rows 25 and 26. They are negative, highlighted in red, and apparently quite large. According to NBER guidelines, two consecutive quarters of declining GDP (GNP) can signal recession ${ }^{27}$.

\section{FIGURE 19}

\section{HYPOTHETICAL POLICY ANALYSIS: THE CONSTANT DOLLAR AE MODEL ON CURRENT ACCOUNT (EXCEL FILE TO TAB 152)}

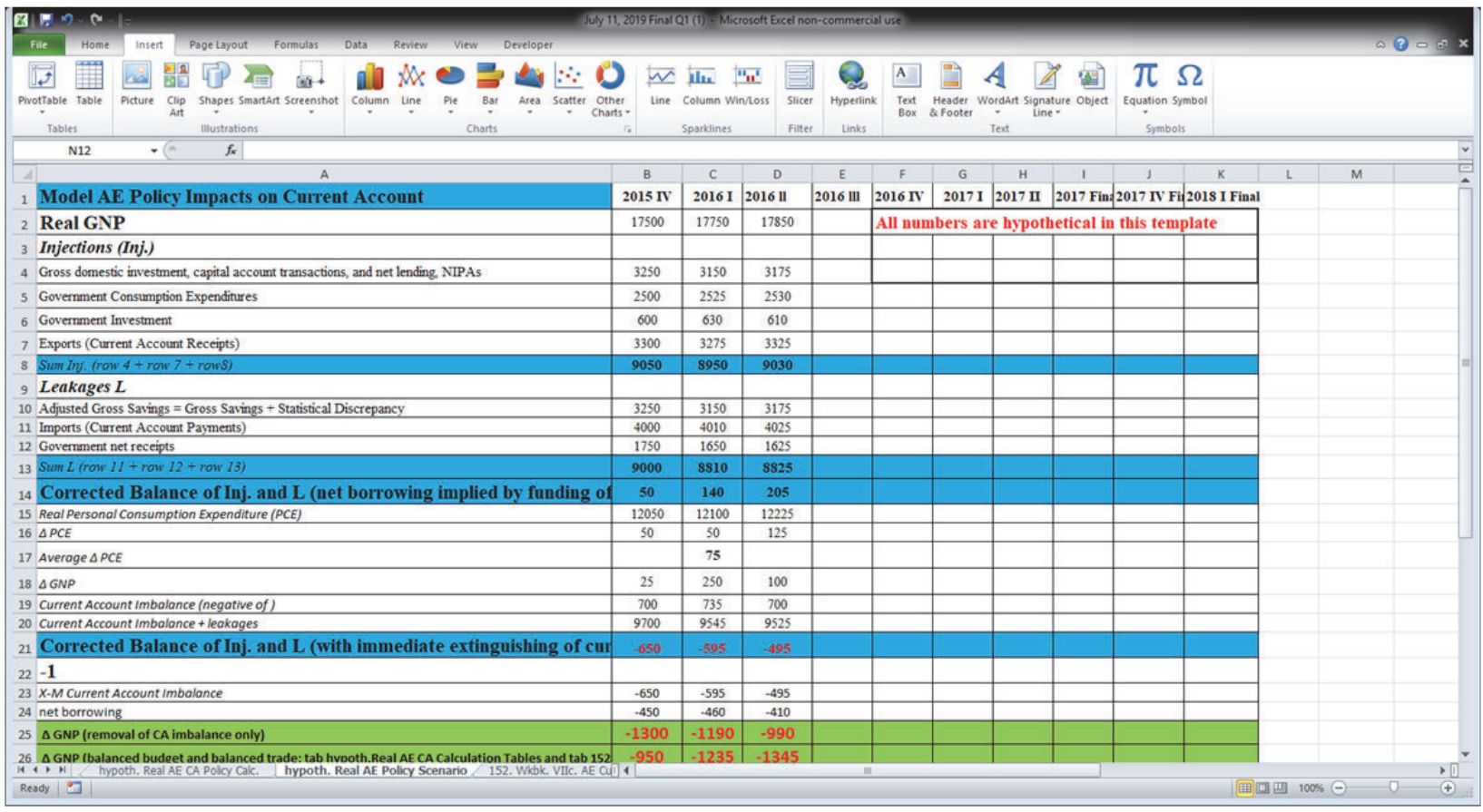

The hypothetical calculation tables which support this template are displayed next. Comments in red are provided to explain the arithmetic found in the spreadsheets and their data sources. Actual data sources trace back to: BEA Tables 1.1.9, 1.5.6, 3.1,4.1 and 5.1 
FIGURE 20

HYPOTHETICAL POLICY ANALYSIS CALCULATION TABLES 1 AND 2: THE CONSTANT DOLLAR AE POLICY MODEL ON CURRENT ACCOUNT (EXCEL FILE TAB 152A)

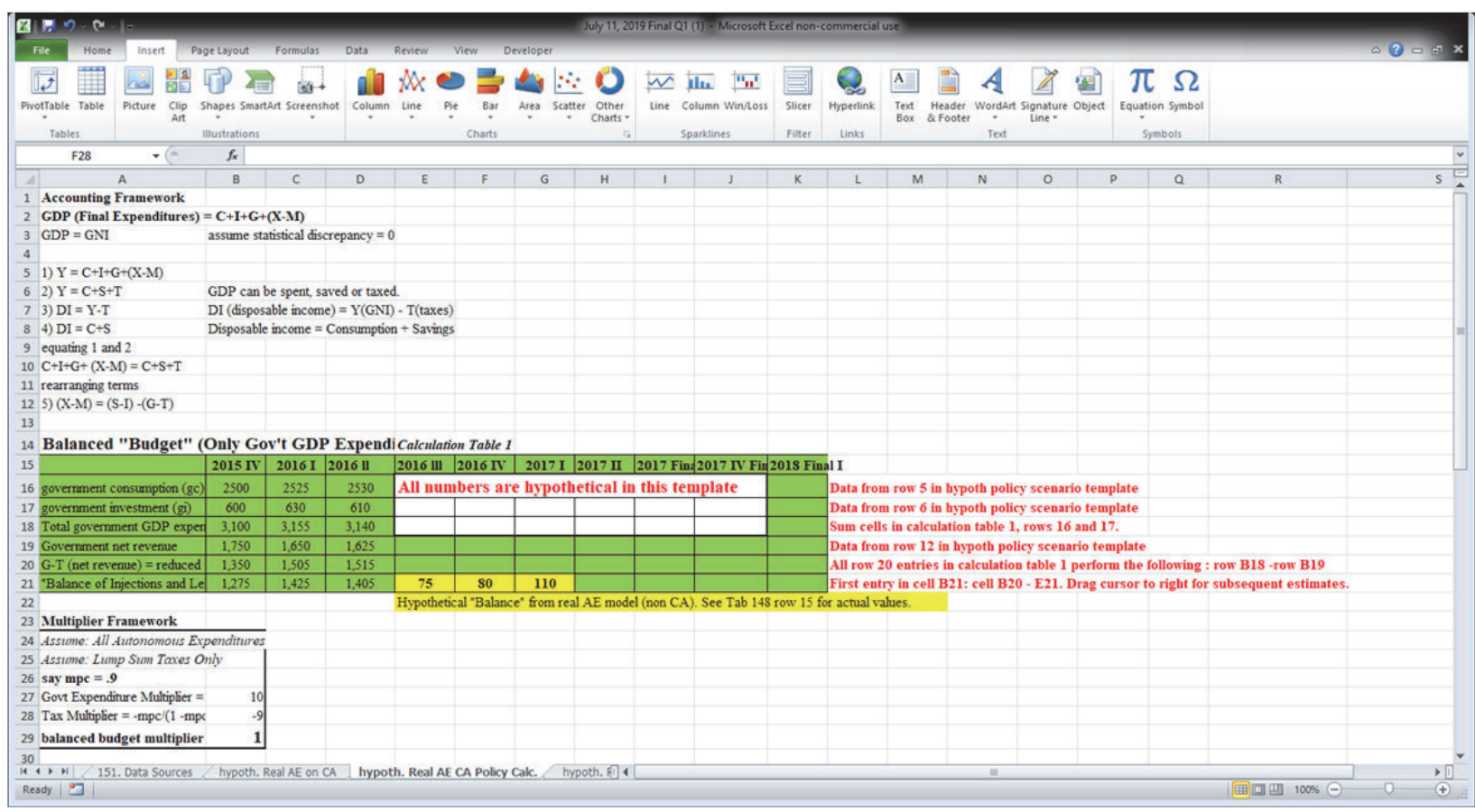

FIGURE 21

(CON'T) HYPOTHETICAL POLICY ANALYSIS CALCULATION TABLES 1 AND 2: THE CONSTANT DOLLAR AE POLICY MODEL ON CURRENT ACCOUNT

(EXCEL FILE TAB 152A)

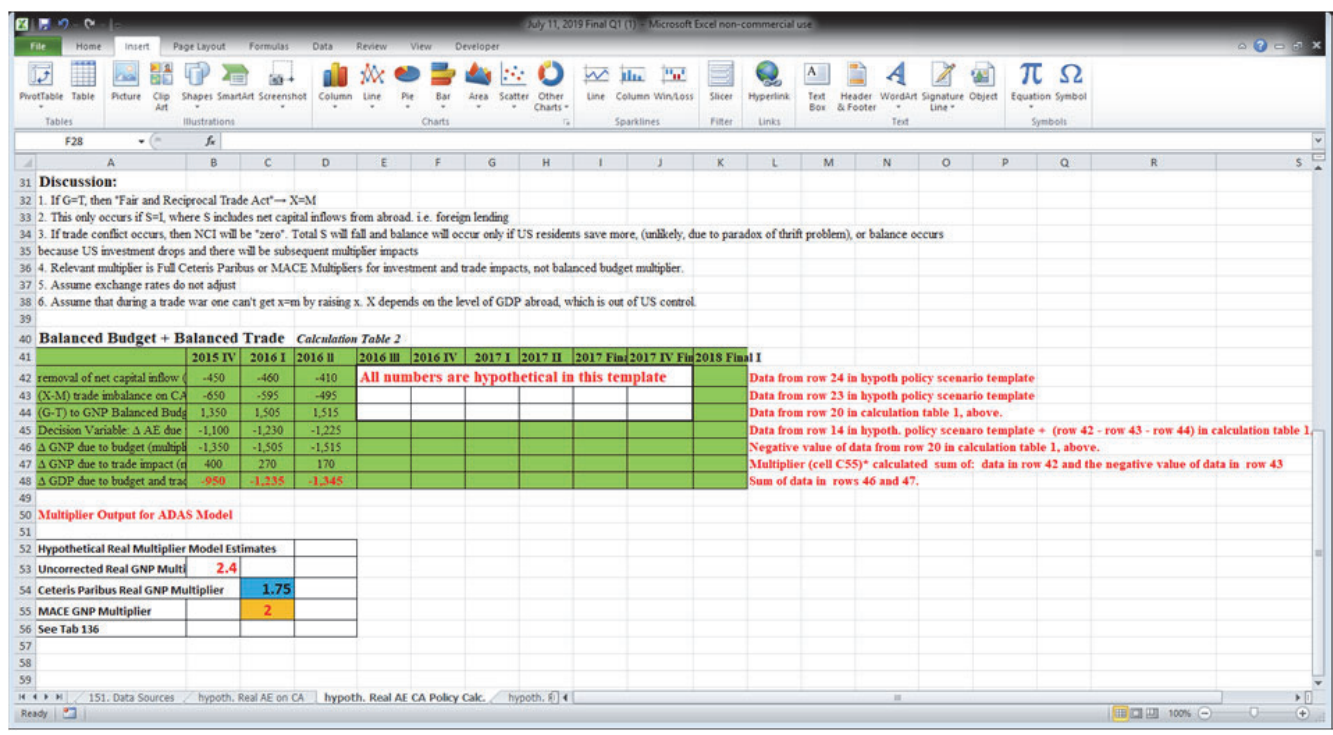

136 Journal of Applied Business and Economics Vol. 21(7) 2019 


\section{CONCLUDING REMARKS}

If the methods and results described above pique your interest, and if you decide to "peek under the hood," remember that the e-book, from which this article is abstracted, should be used in conjunction with one of the representative economic principles texts. As a stand-alone, the basic templates could lack sufficient context. The e-book is a supplement, not a substitute ${ }^{28}$.

Few will find that "diving into the weeds" will be a casual read, but nonetheless the e-book text and spreadsheets do not present an overly difficult challenge if taken step-by-step and in small increments. Practice and patience will make a difference. To insure ultimate success using the AE and ADAS models, in and out of the classroom, the book had to be written as a highly detailed, consistently systematic, carefully argued, and well-documented guide to the procedures and reasoning used to develop and implement data rich templates. It must be the case that readers can avoid guessing and having to fill in the gaps to get up to speed.

Because no prior experience with spreadsheet operations is required, the templates are easily filled in and manipulated. All calculations are embedded in the templates or auxiliary tables; thus, the only operations that need to be mastered by students are: downloading data in Excel; executing copying and pasting commands; coloring cells using "text highlight"; and moving the cursor around. No student/instructor coding is involved. This modest level of skill allows one to be actively and effectively engaged in the data- gathering process. Despite the sheer size of the files, there is no reason to get lost. One should just utilize the guide tabs prior to each template to navigate quickly to the key data, methods and features. To explore specific regions in the templates, the reader can click on individual cells to activate the formula bar. All the trail markers and bread crumbs are there.

It is worth repeating that these routine manipulations produce bottom line results that are firmly connected to the key theoretical concepts discussed or graphed in a standard "principles" textbook. Importantly, this connection necessarily emerges as a byproduct of working through the templates and applying the significant- decision-variable "rules of thumb."

By the end of the semester, I believe that students will be well prepared to progress to more advanced courses in macroeconomics and econometric modeling, should they so choose. Even if this book is their only exposure to the field, once the course is over I am confident that all students will be capable of making informed assessments about the prospects for near term GDP growth, and for explaining what forces are driving the level of aggregate prices and the overall rate of inflation.

\section{ENDNOTES}

1. Those readers who are interested in the specific underlying details can obtain the e-book, its accompanying Excel spreadsheets with quarterly updates, and the eight instructional videos from Kendall Hunt at: he.kendallhunt.com/rubin. Faculty should note that courtesy "desk" copies are also available at this site, or can be obtained by directly contacting the acquisitions editor Ms. Danielle Tunnell at (cellular) $301583-0931$ or at dtunnell@kendallhunt.com

2. Economists do not have a consensus position on what is causing such low and often declining rates of inflation. Typical wage price markup model explanations don't seem overly promising by themselves; but structural changes in the economy, declining union participation, as well as global competitive pressures may offer some additional insight. The jury is still out.

3. There is solid regression evidence pointing to the price level determination mechanism being significantly affected by both excess demand and the verticality of AS curve (as measured by the excess of the natural rate of unemployment (NROU) over the actual rate (ARU). See Tab 169.

4. The components of the Balance of Injections and Leakages are: I,X,G and S,M,T. Ex-post, savings $\mathrm{S}$ always equals investment I. Therefore these two terms can be removed from further consideration without biasing the analysis. After performing an accounting rearrangement, what remains is a hybrid sum of $(\mathrm{X}-\mathrm{M})$ and $(\mathrm{G}-\mathrm{T})$. Doing the actual arithmetic using current data demonstrates that the magnitude of the budget balance (G-T) dwarfs the trade balance (X-M). Hence we identify the template multipliers with fiscal stimulus. 
5. See text pp.34-35, especially Figure 8. For the data, turn to Tabs 22 and 40 in the master Excel file.

6. This approach builds on both of these earlier AE measurements even though the ADAS framework is inherently "constant dollar" (especially the ADAS rate of inflation models). Keep in mind that both nominal and constant dollar estimates of the shift in Aggregate Demand ( $\% \Delta \mathrm{AD}=$ multiplier*B/GDP) are estimated and their resulting impacts on the critical decision variables explored. The need for thoroughness arises potentially when the employment of techniques for smoothing the data impact the "blue shaded" decision variables differentially. That possibility is usually dormant but can't be ruled out when multipliers of different magnitude are employed. Compare Tabs 138 to 139 where data smoothing and the choice of multiplier (ceteris paribus vs. MACE) lead to slightly different results both numerically and in the level of sign consistency.

In practice, the choice between using the "nominal dollar" vs. "constant dollar" shifts may not be a big problem. One can conveniently, but not unreasonably, assume that the overall GDP deflator applies with uniformity across all variables in the "Balance" calculation. As a result of this "default proposition", the ratio "B/GDP" will be the same regardless of whether nominal or constant dollar estimates are used. But even if the assumption is only approximately true, the consequences of making it are not currently going to be dire. This occurs because price increases in the today's environment are already quite modest, and the need to deflate disappears altogether as the overall inflation rate approaches "zero." As a result the excess demand variable: $\% \Delta \mathrm{AD} / \% \Delta \mathrm{AS}$ used in templates IIA.1, IIA.2, IIB and IIC will generally be measured commensurately when using either the nominal or constant dollar values for the individual "Balance" components in AD. Finally, using the above "default assumption" avoids the thorny problem of how to covert nominal dollar estimates into constant dollars when deflating government current net receipts (the values in Table 3.1 used to calculate "T") and adjusted gross savings (the values in Table 5.1 used to calculate "S"). BEA does not publish or endorse any constant dollar versions of Tables 3.1 and 5.1. As a workaround, their recommendation is to consider a range of possible deflators including the overall implicit price deflator index (IPD table 1.1.9) for both " $\mathrm{S}$ " and " $\mathrm{T}$ ) or to use the general IPD index for " $\mathrm{S}$ " and a subcomponent index in Table 1.1.9, specifically devoted to government consumption expenditures, for converting " $T$ " to constant dollars.

7. See the Human Development Index calculated by the UN .

8. For additional considerations, see footnote 21 below.

9. See McConnell, Brue and Flynn 21st edition, especially pp. 232-234. See also: Chiang 4th edition, pp.201-203.

10. The discussion here closely parallels the text on pp.26-28.

11. Students are advised to monitor the consumer/business confidence surveys compiled by the University of Michigan Survey Research Center (www.sca.isr.umich.edu) and The Conference Board. Here one can get signals indicating that autonomous consumption or autonomous investment might be changing. See Tab 45, rows $22-23$

12. The details of the procedure are somewhat lengthy and involved, so the reader is referred to Tabs 3,6 and 7 in the master Excel file.

13. In the opening section of this article, we reviewed the actual estimates and substantiated this provisional claim.

14. A partial exception is the "cumulative growth" model covered in Tab 22. There we propose a time series for the dollar values of AD and AS making comparisons possible. However, these estimates still do not exhibit the full range of hypothesized variation by price at a given moment in time.

15. The "AD/AS" excess demand ratio provides the same information as the typical "AD-AS difference" presentation of the concept.

16. As with the treatment of the multiplier, actual results were reviewed in the opening section of this article to justify the findings.

17. See regression results in order of importance: Tab 169, columns I-Q, rows 2-22; Tab 21, columns A-I, rows 79-98; and Tab26, columns A-I, rows 74-92.

18. This empirical observation is discussed in the e-book text on pp. 29-34 and in Baumol and Blinder pp.206-208.

19. See: e-book text pp. 83-86, Tab 160 and especially Tab 173, columns K-Q, rows 163-177.

20. The growth of rate of $\mathrm{AD}$ is initially estimated in calculation table 1 on Tab 27. There it is assumed that the overall GDP deflator applies globally to all components of the "Balance/GDP" ratio. See footnote labove. 
21. Most economists believe the rate of inflation is a more important macro indicator than the level of the GDP deflator. We don't disagree. Still the aggregate price level is significant in its own right. The templates that deal with monetary issues (IIB and IIC) posit a "money" transactions' demand (Mt) that depends on nominal GDP. By implication, a real GDP quantity index and a corresponding price level (index) are involved. Since the interaction of total money demand and total money supply affects interest rates, this, in turn, could have an impact on the level of investment. Thinking further ahead about the ability to model different legislative policy scenarios, there is a section of the master Excel file and the text that examines how budget and trade balancing initiatives might affect the level of GDP. If the potential recessions that are envisaged in these sensitivity analyses are deep enough, then the level of economic contraction could result in actual deflation. Even a hint that aggregate price levels might decline would certainly get the attention of policy makers at the FED. See Tabs 155-160, and e-book commentary on pp. 81-86.

22. So for reasons of length and clarity of exposition, the presentation of a hypothetical set of calculations and their rationale is omitted. The interested reader is referred to the e-book text pp.43-47 and to Tabs 28 and 29 in the master excel file for an extended treatment

23. Fortunately, all of the AE models reviewed are "ex-post". Hence savings must always equal investment regardless of whether one is analyzing the "private closed" or the "mixed open" economy. In fact the "S=I" equilibrium condition effectively removes these variables from the calculation of the "Balance of Injections and Leakages" since they cancel one another out.

24. For the data (variables) and methods used to convert GDP to GNP, see Tab 126 (Table 4.1, rows 14 and 30) and Tab 129 (Table 1.7.5, rows 8-11) in the master excel file. It is the inclusion of income receipts and payments to the rest of the world found in Table 4.1 that necessitates changing the measure of aggregate economic output found in Table 1.7.5.

25. This identity may be partially obscured when there are certain capital account transactions consisting of capital transfers or the acquisition and disposal of non-produced nonfinancial assets.

26. See Tab 132 and pp. 18-20 in the text.

27. Employment and unemployment measurements are also taken into account.

28. See for instance:

Baumol, W. \& Blinder, A.: Macroeconomics Principles and Policy, Thirteenth Edition (Boston, MA Cengage Learning 2016)

Case, K., Fair, R., \& Oster, S.: Principles of Macroeconomics, Twelfth Edition (Boston, MA Pearson Education, Inc. 2017)

Chiang, E.: Macroeconomics: Principles for a Changing World, Fourth Edition (New York, NY, Worth Publishers 2017)

Hubbard, R. \& O'Brien, A.: Macroeconomics, Sixth Edition (Boston, MA: Pearson Education, 2017)

Krugman, P. \& Wells, R.: Macroeconomics, Fifth Edition (New York, NY, Worth Publishers 2018)

McConnell, C., Brue, S. \& Flynn, S. Macroeconomics Principles, Problems, and Policies, TwentyFirst Edition (New York, NY McGraw-Hill Education 2018) 


\section{REFERENCES}

Baumohl, B. (2012). The Secrets of Economic Indicators, Third Edition. Upper Saddle River, NJ FT Press.

Baumol, W., \& Blinder, A. (2016). Macroeconomics Principles and Policy, Thirteenth Edition. Boston, MA Cengage Learning

Case, K., Fair, R., \& Oster, S. (2017). Principles of Macroeconomics, Twelfth Edition. Boston, MA Pearson Education, Inc.

Chiang, E. (2017). Macroeconomics: Principles for a Changing World, Fourth Edition New York, NY, Worth Publishers.

Hubbard, R., \& O’Brien, A. (2017). Macroeconomics, Sixth Edition. Boston, MA: Pearson Education.

Krugman, P., \& Wells, R. (2018). Macroeconomics, Fifth Edition. New York, NY, Worth Publishers.

McConnell, C., Brue, S., \& Flynn, S. (2018). Macroeconomics Principles, Problems, and Policies, Twenty First Edition. New York, NY McGraw-Hill Education.

Rubin, M. (2019). An Introduction to Macroeconomic Models in Excel: A Data-Driven, Arithmetic Approach for Principles of Economics Students, First Edition. [E-reader Version] (Dubuque, IA Kendall Hunt. Retrieved from: https:// he.kendallhunt.com/rubin 